\title{
The meaning of meaning in biology and cognitive science: A semiotic reconstruction
}

\author{
Göran Sonesson \\ Department of Semiotics, Lund University \\ Box 117, S-221 00 Lund, Sweden \\ e-mail: goran.sonesson@semiotik.lu.se
}

\begin{abstract}
The present essay aims at integrating different concepts of meaning developed in semiotics, biology, and cognitive science, in a way that permits the formulation of issues involving evolution and development. The concept of sign in semiotics, just like the notion of representation in cognitive science, have either been used too broadly, or outright rejected. My earlier work on the notions of iconicity and pictoriality has forced me to spell out the taken-forgranted meaning of the sign concept, both in the Saussurean and the Peircean tradition. My work with the evolution and development of semiotic resources such as language, gesture, and pictures has proved the need of having recourse to a more specified concept of sign. To define the sign, I take as point of departure the notion of semiotic function (by Piaget), and the notion of appresentation (by Husserl). In the first part of this essay, I compare cognitive science and semiotics, in particular as far as the parallel concepts of representation and sign are concerned. The second part is concerned with what is probably the most important attempt to integrate cognitive science and semiotics that has been presented so far, The Symbolic Species, by Terrence Deacon. I criticize Deacon's use of notions such as iconicity, indexicality, and symbolicity. I choose to separate the sign concept from the notions of iconicity, indexicality, and symbolicity, which only in combination with the sign give rise to icons, indices, and symbols, but which, beyond that, have other, more elemental, uses in the world of perception. In the third part, I discuss some ideas about meaning in biosemiotics, which I show not to involve signs in the sense characterised earlier in the essay. Instead, they use meaning in the general sense of selection and organisation, which is a more elementary sense of meaning. Although I admit that there is a possible interpretation of Peirce, which could be taken to correspond to Uexküll's idea of functional circle, and to meaning as function described by Emmeche and Hoffmeyer, I claim that this is a different sense of meaning than the one embodied in the sign concept. Finally, I suggest that more thresholds of meaning than proposed, for instance by Kull, are necessary to accommodate the differences between meaning (in the broad sense) and sign (as specified in the Piaget-Husserl tradition).
\end{abstract}


Often conceived as interdisciplinary perspectives that have in some places gained the position of independent disciplines, cognitive science and semiotics seem to cover more or less the same domain of knowledge. This in itself is controversial, since semiotics and cognitive science offer very different characterisations of their domain. In some sense, however, both are concerned with the way in which the world described by the natural sciences appears to humans beings and perhaps also to other animals and some robots. Cognitive science puts the emphasis on the place of the appearance of this world, the mental domain, ${ }^{1}$ and its characteristic operation, cognition; and semiotics insists on the transformations that the physical world suffers by being endowed with meaning.

The disciplinary history of these approaches has been very different. Cognitive science is often described as the result of joining together the knowledge base of rather disparate empirical disciplines such as linguistics, cognitive psychology, philosophy, biology, and computer science. Semiotics has, in a more classical way, developed out of the amorphous mass of philosophy, and still has some problems encountering its empirical basis. This difference in background partly may explain why semiotics and cognitive science rarely are on speaking terms with each other.

In this essay, I will start out by investigating a case that in some respects go counter to these generalisations. Terrence Deacon (1997) is a researcher in neuroscience whose work has been particularly acclaimed within cognitive science. Yet he has chosen to express some of his main arguments in a terminology taken over from Charles Sanders Peirce, who is perhaps the principal cultural hero of semiotics. Without trying in any way to diminish Deacon's contribution - in fact, I find him very convincing whenever he is not having recourse to semiotic terminology - I would like to express certain misgivings about his way of using Peircean terms. I do not do so in order to defend Peircean orthodoxy (which is a task very far from my mind), but because I think a rigorous use of these terms can throw more light on the issues at stake, and may thus contribute to a more relevant confluence of the two sciences involved. Indeed, I can generally accept the idea, expressed by Bouissac

\footnotetext{
1 A better description of what is involved would be "the field of consciousness", a term used in phenomenology (cf. Gurwitsch 1957), but many representatives of cognitive science would of course not want to use any term referring to consciousness.
} 
(2000: 326), that even if Deacon's usage is not accurate from a Peircean point of view, there is no good reason for rejecting his terms considered as "conceptual facilitators in order to formulate his own evolutionary semiotic theory"; but I think, like Lumsden (2002) that, in this particular case, the Peircean paraphernalia serve to obscure Deacon's own theory, and, unlike Lumsden, I think it is worthwhile to integrate Deacon's problematics with a revised Peircean theory, instead of simple putting it to aside. Rather than taking Deacon to task for not following Peirce strictly, I would like to offer a framework in which both Deacon's problem and that of Peirce may be discussed.

In so doing, I will propose two different interpretations of Peirce, one which I have found necessary in my own work in order to redeem the concept of iconic sign (part 2), and another one which would seem to be common in, among others places, biosemiotics (part 3). However, I will suggest that Deacon's theory is not congruent with any of these interpretations. At the same time, I will try to show that both these concepts of meaning serve to specify Deacon's proposal and place it into a more comprehensive framework.

\section{Introduction: Beyond "representation" in cognitive science}

Before proceeding to our discussion of Deacon's central thesis concerning the nature of symbolism, I would like to delineate the general context within which this discussion will take place. If, as has been suggested above, semiotics and cognitive science have a lot in common, it would be interesting to find out what keeps them apart, and if there is some worth-while manner of overcoming this separation. As a first approximation, it might be suggested that the basic concept of semiotics is the sign, whereas that of cognitive science is representation. From the point of view of methods, semiotics is generally speaking stuck between the analysis of single "texts" and theory construction, whereas cognitive science is closer to relying on experimental methods (including, of course, computer simulation).

In a sense, semiotics keeps making overtures to cognitive science. Even since the demise of the linguistic model, according to which all semiotic systems are constructed more or less in the same way as verbal 
language $^{2}$ (in particular as the latter was conceived in the tradition of structuralism, inspired by Saussure), semioticians have repeatedly stated their ambition of going cognitive. On the whole, it seems to me, there has been little substance to such expressions of intent. Within visual semiotics, my own work aiming to refute the conventionalist theories of pictorial signification developed by, among others, Eco and Goodman (cf. Sonesson 1989a), has relied heavily on findings and concepts taken over from cognitive psychology, notably the work of Rosch (1975a; 1975b; 1975c) and Tversky (1977; Tversky, Gati 1978), but it is, I am afraid, rather unique is this respect. While this work absorbs certain concepts from cognitive science, it also gives more prominence than earlier to the concept of sign. It is more empirical, only in the sense of trying to supply the theory needed to explain experimental findings (which is of course also often true of cognitive science). In a recent anthology bearing the title "cognitive semiotics", Bundgård (et al. 2003), as he notes in the introduction, actually only provides a collection of texts written within the framework of cognitive science which he judges to be relevant to semiotics, which includes the work of cognitive linguists such as Langacker and Fauconnier, and of "catastrophe theorists" such as Thom and Petitot. The latter tradition, which may really qualify as being some kind of hybrid of semiotics and cognitive science, is difficult to situate within both paradigms. In any case, it is not clear that at any given point it has become more cognitive and less semiotical. ${ }^{3}$

On the other hand, there have recently been some encouraging developments within cognitive science which, no doubt with some exaggeration, may be qualified as a "semiotic turn": an interest in meaning as such, in particular as it has developed, ontogenetically and, in particular, phylogenetically, in the human species and, to some extent, in other animals and animal-like machines. Not only Deacon, both other scholars interested in the specificity of human nature now put their emphasis on the concept of sign (which they normally term "symbol", using this word is a sense in which we will not employ it here). This is

2 As used here and in the following, the term "verbal language" includes gesture systems and the like, which are formally equivalent to spoken and written language. In a semiotic context, the label "verbal" is necessary in order to exclude more metaphoric uses of the term "language".

3 Catastrophe theory has certainly become less involved with Gremasian semiotics, but the latter cannot be identified with semiotics tout court, as Bundgaard seems to think. 
true, in a very general sense, of Donald's (1991) stages of episodic, mimetic, mythic and theoretical culture. It seems to apply even more to Tomasello (1999), less, in the end, because of his epigraphs taken from classical semioticians such as Peirce and Mead as well as Bakhtin and Vygotsky, than because of the general thrust of his analysis, which consists in separating true instances of interpreting actions as intentional from those which may merely appear to be such. Building on the aforementioned works, Jordan Zlatev (2002; 2003) is explicitly concerned with the conditions for the emergence of higher levels of meaning involving "mimesis" and language, from more basic ones, characteristic of all biological systems (life forms), such as "cues" and "associations". Although he has not proposed any complete scheme for developmental semiotics, Tom Ziemke (Ziemke, Sharkey 2001; Lindblom, Ziemke 2003) no doubt must be said to participate in the suggested "semiotic turn" already because he has had recourse to the concepts of Uexküll and Vygotsky in order to separate living beings from robots.

The distinction between cognitive science and semiotics involves much more than the concepts of representation and sign, as was suggested above. Indeed, much of recent cognitive science has taken the form of a rejection of the very notion of representation (notably the influential work of Lakoff and Johnson; cf. Lakoff, Johnson 1999; Johnson 2005), just as some traditions in semiotics, from Eco to Greimas, early on rejected the notion of sign. In both cases, as we shall see, the problem is how one can reject a notion which is not even defined, but simply taken for granted. However, in this article, the relationship between the two disciplines will be discussed exclusively in these terms. To a representative of cognitive science, it may seem that "sign" and "representation" stand for the same thing. If so, it is difficult to see in which way the work of Deacon, Donald, Tomasello, Ziemke, and Zlatev constitutes a kind of "semiotic turn".

In cognitive science, terms like "representation", "symbol", and even "sign", are used in a vastly more comprehensive sense than the one favoured here. The contents of consciousness are said to be "symbols", and so on, of things in the "real" world (see Johnson-Laird 1988). Even

4 Zlatev (2003) now distinguishes "signs", as the general term, from "symbols", which are truly conventional, systematic and possibly arbitrary signs. His terminological usage is thus intermediate between that of Deacon and that of Peirce (employed here). 
in a recent textbook (Eysenck, Keane 1995: 203ff), representations are only distinguished into those that are external, such as pictures and language, and those that are internal, such as propositions and mental models. Interestingly, this is an employment of the terms "sign" and "representation" found also in John Locke, one of the first explicit semioticians, at the beginning of the 18th century. Indeed, Locke's (1965 [1706]: 309) definition of semiotics may actually sound more like a characterisation of cognitive science: it is, together with physics and ethics, a third part of all human knowledge, the business of which is "to consider the nature of signs the mind makes use of for the understanding of things, or conveying its knowledge to others."

Even before that, however, Pedro Fonseca, in his treatise on signs from 1564, distinguished two types of signs: "formal signs", by means of which we know the outside world, and "instrumental signs", which lead to the cognition of something else, like the tracks of an animal, smoke, a statue, and the like (cf. Deely 1982; 1994; 2001). This distinction could perhaps be taken to correspond to that between "internal" and "external representations". However, it seems more akin to a distinction between "direct" and "indirect perception", as suggested by the psychologist of perception James Gibson, in his discussion of the differences between the environment and those kinds of surfaces that we call pictures. As recognised in the ecological psychology of Gibson, and before that in the philosophical phenomenology of Edmund Husserl, we do not ordinarily perceive signs of the world, but the world itself; and thus, if indeed meaning is involved, this must be is some wider sense of the term. Both Husserl and Gibson point out that we do not perceive "this flurry collection of surfaces seen from above right", but a dog, even if the former expression may better describe the collection of light rays which hit the eye. ${ }^{5}$ More generally, Peirce and Vygotsky alike introduced the term "mediation" to describe the way in which reality is imbued with meaning. At least, as we shall see, this is one possible interpretation of what their intentions were. ${ }^{6}$

\footnotetext{
5 Although Gibson (1966; 1982) never quotes Husserl, the similarity between the two thinkers extends onto their very formulations. Apparently, he was less taciturn about his sources during his lectures, as suggested by the fact that his students point to Husserl's influence (cf. Lombardo 1987; Reed 1988: 45).

6 In spite of the suggestion made by several authors in Mertz, Parmentier (eds. 1985), mediation did not mean the same thing to Vygotsky and to Peirce. In particular, it may appear from certain passages in Peirce's work that there is nothing that is not mediated, that is, nothing that is opposed to mediation. However, this
} 
What is interesting about Deacon, Donald, and Tomasello from a semiotic point of view is that they do appear to talk about signs (or "symbols") in the sense of mediation. But this concept is not spelled out, nor clearly distinguished from other concepts of meaning. ${ }^{7}$ This is the task I have set myself in the present essay.

Just as cognitive science has absorbed the themes of embodiment and situatedness from phenomenological philosophy (notably in Varela et al. 1991), it needs to take over the concept of semiotic function, which, as I have reconstructed it in my own work, stems in part from phenomenology, and in part from the cognitive psychology of Jean Piaget. Indeed, as we shall see, much of semiotics, too, is content to use the concept of sign or mediation, without asking itself what criteria serve to define it. Be that as it may, it will be suggested in the following that, in important respects, the "semiotic turn" to which the work of Deacon and others testify does not go far enough.

\section{In defence of the sign: A critical reading of Deacon's use of Peircean terminology}

Although I intend to show, in the following, that Deacon's use of Peirce's concepts is not consistent with a natural interpretation of Peirce, and therefore is seriously misleading, I am not out to defend Peircean orthodoxy as such. It is important to point this out, since there certainly are semioticians who look upon Peirce's writings the way many Christians conceive of the Bible, as Divine revelation. In contrast, in my view it is not interesting to find out "what Peirce really thought", except perhaps as a kind of preparation for our own analysis. Peirce was no doubt an exceptional thinker, who, moreover, consecrated most of his life to reflecting on the nature of meaning. There is therefore every

interpretation fails to account for the notion of iconicity, to which we will turn below. To Vygotsky (1962; 1978), however, mediation basically seems to involve language, in the strict sense of the term (although there are references to other semiotic resources which are not properly taken into account).

7 Zlatev certainly focuses on different concepts of meaning, and, in his latest paper (Zlatev 2003), even distinguishes signs and symbols, but not quite in the way it is done here, although I pride myself of being at least one of the causes for the introduction of this distinction. I cannot further discuss this terminology here. As for Ziemke's use of the term "sign", which derives from Uexküll, I will touch on it in the third part of this essay. 
reason to take his opinions into account, even if, in the end, we decide to revise them.

\subsection{How to make Deacon's (and Peirce's) ideas clear}

Peirce famously pinpointed the importance of having a correct terminology for making our ideas clear. It can be observed with some justification that, in this task, Peirce himself failed miserably. Few things have turned out be more open to misapprehension that Peirce's own terminology. Yet I think the injunction as such should be taken seriously. There are at least three reasons for pointing to the discrepancy between Deacon's and Peirce's employment of the same terms. First, using terms already having a more or less established signification within Peirce scholarship in other meanings breeds confusion. Second, it tends to obscure the basic issues of Peirce's theory. Third, it renders Deacon's own problem difficult to grasp. Indeed, I will argue that Deacon has no use whatsoever for Peircean terms, since he is concerned with different issues. And yet both Deacon's and Peirce's problems are important. And, within a more comprehensive theory, they should be connected. ${ }^{8}$

There are different possible formulations for what we have so far called Deacon's problem: how it is possible for the child to learn a language, without having a Chomskyan Language Acquisition Device; how human intelligence can be so special if, within the brain, only a quantitative difference to other species can be found; how the difference can be so important, if the human brain is not even the biggest of any species, whether in absolute terms, or in relation to body mass; and so on. But there is yet another formulation, which will serve as my point of departure here: why there are no "simple languages", that is, nothing which is similar to (verbal) language, but containing fewer signs and/or less complex rules (Deacon 1997: 39ff). Or, as Deacon himself puts it:

Imagine a greatly simplified language, not a child's language that is a fragment of a more complicated adult language, but a language that is logically complete in itself, but with a very limited vocabulary and syntax, perhaps sufficient for only a very narrow range of activities. [...] Even under these loos-

8 I will be mostly concerned here with chapter 3 of Deacon's book, to which will be added some earlier and later passages. This essay thus covers a very small part of Deacon's theory, but one that is essential for preparing an encounter between cognitive science and semiotics. 
ened criteria, there are no simple languages used among other species, though there are many other equally or more complicated modes of communication. (Deacon 1997: 40f) ${ }^{9}$

Deacon here presupposes a certain concept of language, which is spelled out a little later: it is "a mode of communication based upon symbolic reference (the way words refer to things) and involving combinatorial rules that comprise a system for representing synthetic logical relationships among these symbols" (Deacon 1997: 41). He goes on to say that this concept extends beyond verbal language to include such things as "manual signing, mathematics, computer 'languages', musical compositions, religious ceremonies, systems of etiquette, and many rule-governed games" (Deacon 1997: 41). Even so, he contends, language is not found in other species. To refute this argument, it should be sufficient to discover language-like systems having reduced complexity and/or a smaller quantity of units, comparable to what we find in children. According to Deacon, however, nothing like this can be found, not even in the case of animals that, with extraordinary efforts, have been explicitly taught to use some units derived from language. The animals fail to use these units as part of a language system. This is true also of animals that are able to learn other complex behaviour patters and to remember extensive sets of associations. Thus, their inability to learn language does not derive from a general incapacity to handle complexity as such or to sustain an important memory load.

It is misleading, Deacon (1997: 52ff) goes on to say, to use language (which he here identifies with "vocal communication") as a model for analysing other forms of communication, such as those found in ani-

9 Although Deacon initially appears to claim that what he calls "simple languages" do not exist, what he really wants to say is that they only exist in human beings (as mentioned in the very quotation to which this note refers: "no simple languages used among other species" (my italics). As noted already in the passage quoted, children's language really is a case in point. This becomes even clearer in chapter four (in particular 122ff), where Deacon suggests language learning is possible because the child starts out ignoring the more complex aspects of language. Even if we take into account the restriction to "a language which is logically complete in itself", simple languages will not disappear from the world, because they reappear in human evolution, if Deacon (1997: 340) is right in positing a mutual development of language and the brain. As mentioned below in the text, Deacon's exclusion of "simple languages" in animals only applies "in the wild", as testified by laboratory cases such as Kanzi and others. 
mals. Language is exceptional, and has been around for a much shorter time than other kinds of communication. When we teach a dog to obey a command in verbal language, we understand what it means, but the dog learns it "by rote". What for us depends on language, involves another kind of communication system for the dog.

In spite of the attempt at a definition, it cannot be said that Deacon's concept of language becomes particularly clear. Sometimes, it seems to involve only "vocal communication", but at other occasions it appears to be very extensive indeed. When Deacon mentions "religious ceremonies, systems of etiquette, and many rule-governed games", it is difficult not to see this as an echo of Saussure's very tentative characterisation of the subject matter of "semiology", which includes at least the first two, and perhaps also the third, instantiated by the game of chess. Other semioticians, even a close follower of Saussure such as Hjelmslev, would have excluded these cases from the domain of true signs, because, in his view, they lack "double articulation". ${ }^{10}$ Today we also have a speciality that is called semiotics of music, but not all semioticians are sure whether there can be such a domain of study. Indeed, one may wonder whether Deacon himself (no doubt in very good company) does not himself extend the language metaphor excessively.

In contrast with this pansemioticism, and no doubt much to the chagrin of biosemioticians, Deacon denies any kind of semiotic character to the kind of communication processes occurring in the world of animals. ${ }^{11}$ He would deny that the relationships between cells is a process of interpretation (a Peircean semiosis) as Hoffmeyer would have it; nor would he discover any "symbolic reference" in the genetic code, contrary to what was famously suggested by Roman Jakobson. In fact, he does not even discuss what, in Sebeok's parlance, is called "endosemiotic" processes (sign processes occurring within the body). What is at stake is the domain of zoosemiotics as originally characterised by Sebeok, that is, those overt stretches of behaviour which serve to convey meaning, in some sense or other, from one animal to another, e.g. the

\footnotetext{
10 That is, once they have been separated into signs with expression and content, there is no point continuing to analyse expression and content separately, into smaller units that do not coincide on the two levels. See my discussion of the semiotic function below.

11 I here suppose that, if Deacon had used the term, he would define semiotics as the domain of "symbolic reference". It is of course possible that Deacon would instead oppose symbolic semiosis to other kinds of semiosis, such as that found in animal communication systems.
} 
cry of the wolf, the calls of vervet monkeys, the dance of the bees, and so on.

As will be seen later, I think Deacon is quite right in excluding such phenomena as these, if not from the domain of semiosis generally, at least from that characterised by the concept of sign. The trouble is that these distinctions appear to be quite arbitrary, as long at the notion of "symbol" (that is, in my terminology, the sign) is not defined. To characterise it as "the way words refer to things" begs the question, to say the least. This is also true of the opposition between "this unique human mode of reference" and "forms of nonsymbolic reference that are found in all nonhuman communication (and in many other forms of human communication as well)" (Deacon 1997: 43).

However, in the same context, Deacon points out that the problem for the animals is "the simple problem of figuring out how combinations of words refer to things", and he goes on to argue that grammatical rules and categories are only physical regularities if they are considered independently of symbolic operations. This is an important factor, as we shall see later, which has to do with the systematicity of verbal language and some other semiotic systems, but it is not in any direct way connected with symbolicity, in Peirce's sense of the term.

It is difficult to see how etiquette rules, games (such as chess) and music would have "symbolic reference", in a way in which animal communication systems fail to have it. In fact, if we suppose "symbolic reference" to convey the general idea of something being "about" something else, or, equivalently, to stand for something else, then it makes much more sense attributing it to at least some instances of animal communication than to such things as etiquette, games, and music. ${ }^{12}$ Etiquette rules and the rules defining games are not "about" anything at all: they impose restrictions on the behaviour allowed. As Deacon (1997: 61) claims about laughter, it is certainly odd to say that etiquette has a meaning, at least in the sense of reference. Indeed it might be argued (and we will return to this later) that to the extent that there is something semiotical about these phenomena, it is found at a level comparable to endosemiotics.

\footnotetext{
12 As becomes clear at least in the discussion of the Williams syndrome, Deacon (1997: 270) would associate such "aboutness" with indexicality, not symbolicity. This is a serious error, because it amounts to confusion between indices and indexicality. As we will see later, it is not an accident that Deacon has recourse to the same examples as Saussure.
} 
What is even more curious is that, when Deacon (1997: 59ff) later returns to "the reference problem", he opposes "the way words refer to things" to "a vervet monkey alarm call, a laugh, or a portrait". No matter what features we attend to, the portrait, just as any other picture, undoubtedly refers in a way much more similar to words, than does either a laugh or a rule of etiquette. Indeed, Deacon would seem to agree with this. Later on in the text, Deacon (1997: 365f) talks about "external symbolization in the form of paintings, carvings, or just highly conventional doodlings" which are "the first concrete evidence of the storage of such symbolic information outside of the human brain" (Deacon (1997: 374, my italics). We will return to this issue when discussing the concept of semiotic function. ${ }^{13}$

Deacon does not give any further justification for classifying games, etiquette, and music with language, while excluding pictures, but it might be argued that, although games and etiquette rules (and perhaps even music) are not prototypical signs, such as verbal language and pictures, they are still "about" something in some more general sense. ${ }^{14}$ To shake hands (in a given context) means that you greet somebody; to move a particular chessman means that the queen takes up a new position causing perhaps a checkmate. As I understand the term "etiquette rules" (but Deacon gives us no clue) is does not involve something like shaking hands. I would describe this as an interactive gesture carrying a meaning just as any other sign. Etiquette rules, however, are those that tell us under which circumstances it is appropriate to shake hands, and when it is not. In this sense, they impose restrictions on the behaviour allowed. $^{15}$

The case of chess, however, is more difficult to deal with. What makes some pieces of wood or other material and a board into a game of chess are the restrictions imposed on the permitted movements of the chessmen and the consequences of certain chessmen taking up particular positions. Saussure would seem to use the example of chess as an

13 The passage quoted introduces a section that is concerned to show that there is more to the purported difference than conventionality. So perhaps Deacon would say that etiquette, just as language, is part of a system, whereas neither laughs nor pictures are. But this only shows that his terms and his criteria are unclear.

14 I owe these objections, as well as the examples quoted in the sequel, to Jordan Zlatev.

15 This is equivalent to the "display rules", which, according to Ekman and Friesen (1969), are applied differently in different cultures to the universal facial expressions for emotions. 
analogue to phonology rather than semantics: anything is a queen, as long as it is permitted to move it in the ways a queen moves, just as anything (with some exaggeration, no doubt) may be an /a/, as long as it functions as an /a/ in the vowel system. Hjelmslev, however, claims that chess is a "symbol system", in the sense of permitting no distinction between expression and content, itself a result of both having the same structure (i.e. of not being doubly articulated). ${ }^{16}$ As we will see below (in 2.2), this is not, in my view, a valid argument for abandoning the difference between expression and content. In fact, as Searle has observed, the rules of chess are not like traffic regulations, applying to movements on a board which were hitherto unregulated: the restrictions on movement create chess, but traffic regulations do not create traffic. ${ }^{17}$ Clearly, it could be argued that the queen means "able to move in any straight direction as far as desired", in a sense in which /a/ does not mean "low, frontal, sonorous". However, it does not seem that each movement of the queen could be a kind of "chess act", comparable to a speech act, in case of which chess would be a highly repetitive type of discourse. It might be admitted, therefore, that chess is in some way intermediate. But this does not change the fact that pictures are much more similar to language, in this respect, than chess is.

Apart from having language, human beings retain some elements of a communication system comparable to that found in animals. It is wrong, Deacon (1997: 53f) thinks, to see these systems as partial languages, or precursors to language, because they are in fact selfsufficient and independent of language, even in man. Language, on the other hand, needs the support of these systems, because "we make extensive use of prosody, pointing, gesturing, and interactions with objects and other people to disambiguate our spoken messages". It would be absurd, in Deacon's opinion, to see smiles, grimaces, laughs, sobs, hugs, kisses, and the like, as "words without syntax". Without bothering to do the latter, I still find Deacon's idea of a "special kind of reference" difficult to grasp. Most instances of pointing and many instances of gesturing and interactions with objects seems to me to have something akin to "symbolic reference" (cf. Kendon 2004; Kita 2003), whereas one would be hard pressed to find something of the kind in sobs, hugs and

\footnotetext{
16 This is of course a sense of symbol that has nothing to do with the use of the term neither in Peirce, Saussure, or Deacon.

17 In the Pufendorf lectures, given at Lund University, May 30 to June 2, 2006. This is an example of his old distinction between constitutive and regulative rules.
} 
kisses - none if which serves to suggest that the latter are not meaningful.

However, the example of the vervet monkey alarm calls may contribute to a clarification of the issue. Seyfarth, Cheney et al. (as reported in Deacon 1997: 54ff; also cf. Hauser 1997) tell us that these monkeys produce different calls to warn troop members of the presence of either eagles, leopards, or snakes. The calls have the effect of making the troop members race out of threes, climb into the trees, or just rise up to peer into the bushes around them. These calls therefore do not simply refer to states of mind (fear in all cases) but to different predators. ${ }^{18}$ According to the authors, the calls are analogous to names, or to the way we use the exclamation "Fire!", and thus they make up a simple language. However, they also point out that the calls are different from language in being contagious. At the same time as they behave in the adequate way, the monkeys repeat the calls. This is more similar to our way of laughing, as Deacon points out. To laugh at something is quite different from saying "I just heard a great joke". There is a sense, Deacon (1997: 57) admits, in which a laugh may be said to refer to "a definite class of experiences which are deemed funny". Analogously, the vervet monkey calls refer to classes of predators. But this is not the same sense in which words refer. ${ }^{19}$

Later on, when opposing "sense" and "reference" in the Fregean sense, Deacon (1997: 62) seems to say that laughs and vervet monkey alarm calls, contrary to words, do not need any "sense" to determine the "reference". Yet he already appears to have admitted the opposite when claiming that there is a sense in which laughs refer to a class of laughable objects. This would seem to be analogous to the way in which words which change their meaning (or reference) each time they are used (Husserl's “okkasionelle Bedeutungen", Jespersen's and Jakobson's "shifters", etc.) are said to signify "the class of all persons referring to themselves", "the class of all present moments", etc. In both cases, only

18 In fact, they could also be said to refer to different behaviour patterns, that is, as Peirce would have said, to different energetic interpretants.

19 Another criterion quoted here by Deacon (1997: 58f) is the hierarchy of intentions according to Grice. I will ignore it here, because it certainly does not put pictures or any kinds of gesture in a different class from verbal language. Cf. Sonesson 1999, 2001a, 2002. In fact, I suspect most instances of kissing, embracing and even prosody must be deemed to be hierarchically intentional. 
one of those objects is picked up in the moment of realisation..$^{20}$ It is true, however, that Deacon says laughing and alarm calls fail to have any "conscious concept of meaning" (my italics). Perhaps this should be understood in the sense in which Deacon (1997: 63) goes on to say that the difference between a dog's and a human being's way to get to the reference is "something additional that is produced in the head". But, again, this is a claim in need of further elucidation.

Deacon then introduces the Peircean concept of interpretant to take care of this mental residue. This is rather unfortunate, for, if anything, the interpretant is not characterised as being mental. The different behaviour sequences provoked in the troop by the various vervet alarm calls would be ideal cases of Peircean interpretants. It is true that Deacon later notes that there are different kinds of interpretants in Peirce's theory. But he then goes on to talk as if only words had interpretants. However, Peirce's original point was quite the opposite one: that meaning is not necessarily "in the head". It is no accident that Morris could reinterpret Peirce using the tenets of behaviourist psychology. It is not even true that the chain of interpretants, where one instance leads on to another, and so on (for instance one word to another), is characteristic of language, as Deacon seems to think. In Peirce's view, it would apply to all signs (including "non-symbolic communication"). Nor is Peirce interested in distinguishing interpretants in a way that would be useful to Deacon. His taxonomy obeys different criteria that do not pertain to the distinction between language and other communication forms, nor to the difference between mental phenomena and others. As Peirce never tires of explaining, the mind is simply a possible instance among others of an interpretant.

According to Deacon (1997: 63), "an interpretant is whatever enables one to infer the reference from some sign or signs and their context". This is perhaps not wrong, but it is misleading. Rather, the interpretant is any consequence the sign may have for somebody doing the interpreting. The distinction between interpretant and object has nothing to do with the Fregean opposition between sense and reference, contrary to the impression one may get form reading Deacon (and of course from the classical model of Ogden and Richards). If anything, Frege's terms

20 I am of course not claiming any further analogy, but it would seem that Deacon would have to do so. Both cases are indexical to him, as we will see later, whereas I would insist on the difference between a mere indexical relation (an indexicality) and an indexical sign (an index). 
would rather correspond to the distinction between the immediate object (that which is directly presented through the sign) and the dynamical object (that which we may learn by other means about the thing presented by the sign). Everything really tends to suggest that, to Peirce, the object is that which incites someone to create a sign; and the interpretant is something which the sign gives rise to in the one being presented with the sign. We will see this more in detail in a later section of this essay.

For the moment, however, I think we need to introduce a clear concept of what a sign (in some respects equivalent to Deacon's "symbol") is. Then we shall see that the sign, rather than being identified with one of Peirce's categories, must be cross-classified with iconicity, indexicality and symbolicity. And finally we shall see that even symbols in our sense, which combine the semiotic function with symbolicity, are not confined to verbal language. Something else must be added, which Deacon fails to distinguish clearly.

I will start out from a definition of the semiotic function that I found necessary to introduce, in order to salvage the notion of iconicity from the conventionalist critique of Eco and Goodman (cf. Sonesson 1989a, etc.).

\subsection{Stone for candy and feathers for a chicken. On the concept of semiotic function}

Even though semiotics is not exclusively concerned with signs, but is also required to attend to meanings of other kinds, the concept of sign remains crucial, and semiotic inquiry still has to start out from a distinction between signs and other meanings (cf. Sonesson 1989a; 1992a; 1992b; 1998a). Indeed, many semiotic studies (those of Lévi-Strauss, Barthes, the Greimas school, and, most notably perhaps, those forming part of biosemiotics), will recover their validity, once it is realised that they are concerned with meanings, in a much wider sense than that of the sign, better paraphrased perhaps in terms of wholes, connections, or schemes. Building their models of the sign, both Peirce and Saussure made a set of fundamental conceptual distinctions, which are in part complementary, yet both of them took if for granted that we would all understand the import of such terms as "signifier" and "signified", or the equivalent. A basic understanding of the sign function may however 
be gained from an interpretation of Piaget's important attempt to define the semiotic function (which, in the early writings, was less adequately termed the symbolic function), and from Husserl's definition of the notion of appresentation.

According to Piaget, the semiotic function is a capacity acquired by the child at an age of around 18 to 24 months, which enables him or her to imitate something or somebody outside the direct presence of the model, to use language, make drawings, play "symbolically", and have access to mental imagery and memory. The common factor underlying all these phenomena, according to Piaget, is the ability to represent reality by means of a signifier that is distinct from the signified. ${ }^{21}$ Indeed, Piaget argues that the child's experience of meaning antedates the semiotic function, but that at this stage it does not suppose a differentiation of signifier and signified in the sign (see Piaget 1945; 1967; 1970). ${ }^{22}$ Even from a cursory interpretation of these terms, it seems clear that pictures as well as linguistic signs, some kinds of play (but not games such as chess) and certainly some gestures depend on the semiotic function; but etiquette rules and most instances of music do not.

In several of the passages in which he makes use of this notion of semiotic function, Piaget goes on to point out that "indices" and "signals" are possible long before the age of 18 months, but only because they do not suppose any differentiation between expression and content. The signifier of the index is, Piaget (1967: 134; my translation, G. S.) says, "an objective aspect of the signified"; thus, for instance, the visible extremity of an object which is almost entirely hidden from view is the signifier of the entire object for the baby, just as the tracks in the snow stand for the prey to the hunter. But when the child uses a pebble to signify candy, he is well aware of the difference between them, which implies, as Piaget (1967: 134ff) tells us, "a differentiation, from the subject's own point of view, between the signifier and the signified".

21 It should be noted that at least memory and mental pictures are internal representations, in the sense of cognitive science, but that they are still differentiated, according to Piaget's conception.

22 Not all of Piaget's examples of the semiotic function may really be of that kind, even applying his own criteria. For some critical observations, see Bentele 1984; Trevarthen, Logotheti 1989; Sonesson 1992b. Just as it remains doubtful that there is a unitary semiotic function from the point of view of ontogeny, as Gardner and Wolf (1983) observe, one may doubt its phylogenetic justification (cf. Foley 1991). However, this does not necessarily put into doubt the structural unity of the function. 
Piaget is quite right in distinguishing the manifestation of the semiotic function from other ways of "connecting significations", to employ his own terms. Nevertheless, it is important to note that, while the signifier of the index is said to be an objective aspect of the signified, we are told that in the "sign" and the "symbol" (i.e. in Piaget's terminology, the conventional and the motivated variant of the semiotic function, respectively ${ }^{23}$ ) expression and content are differentiated from the point of view of the subject. We can, however, imagine this same child that in Piaget's example uses a pebble to stand for a piece of candy having recourse instead to a feather in order to represent a bird, or employ a pebble to stand for a rock, without therefore confusing the part and the whole: then the child would be employing a feature, which is objectively a part of the bird, or the rock, while differentiating the former from the latter from his point of view. Only then would he be using an index, in the sense in which this term is employed (or should be employed) in semiotics (cf. Sonesson 1992a; 1992b; 1995b). ${ }^{24}$

Just as obviously the hunter, who identifies the animal by means of the tracks, and then employs them to find out which direction the animal has taken, and who does this in order to catch the animal, does not, in his construal of the sign, confuse the tracks with the animal itself, in which case he would be satisfied with the former. Both the child in our example and the hunter are using indices, or indexical signs. On the other hand, the child and the adult will fail to differentiate the perceptual adumbration in which he has access to the object from the object itself; indeed, they will identify them, at least until they change their perspective by approaching the object from another vantage point. And at least the adult will consider a branch jutting out behind a wall as something

\footnotetext{
23 Piaget thus uses the term "sign" to stand for, among other things, an entity consisting of an expression and a content that are connected to each other arbitrarily, and "symbol" for an entity having a non-arbitrary connection, exactly as Saussure does. To Peirce, as we shall see, "sign" is a generic term, and "symbol" applies, roughly speaking, to an entity based on an arbitrary connection (or, perhaps more generally, a "law-like" connection). Deacon does not distinguish between "sign" and "symbol" in their Peircean senses. In this essay, I follow Peirce's usage, though I try to give a more precise meaning to the concept of sign.

24 In fact, the child may even try to objectify his subjective point of view in the sign, by reworking the pebble to resemble a rock, or by transforming (less plausibly) the feather into the likeness of a bird. This is the kind of discovery made by the prehistoric artist, although the rock itself may not really have been a possible subject matter to him.
} 
that is non-differentiated from the tree, to use Piaget's example, in the rather different sense of being a proper part of it. This is so because, from the point of view of phenomenology, defended by Gibson as well as Husserl, the part is no sign of the whole, but is identified with it in perception. ${ }^{25}$ In the Peircean sense an index is a sign, the relata of which are connected, independently of the sign function, by contiguity or by that kind of relation that obtains between a part and the whole (henceforth termed factorality). But of course contiguity and factorality are present everywhere in the perceptual world without as yet forming signs: we will say, in that case, that they are mere indexicalities. Perception (to pick a Peircean term) is profused with indexicality (cf. Sonesson 1989a; 1992a; 1992b; 1995b).

Each time two objects are perceived together in space, there is contiguity; and each time something is seen to be a part of something else, or to be a whole made up of many parts, there is factorality. According to Husserl, two or more items may enter into different kinds of "pairings", from the "paired association" of two co-present items (which we will call perceptual context), over the "appresentative pairing" in which one item is present and the other indirectly given through the first, to the real sign relation, where again one item is directly present and the other only indirectly so, but where the indirectly presented member of the pair is the theme, i.e. the centre of attention for consciousness. This property serves to distinguish the sign from the abductive context, which is the way in which the unseen side of the dice at which we are looking at this moment is present to consciousness: in the abductive context the attention is focused on the directly presented part or spans the whole context. However, there seems to be many intermediate cases between a perfect sign and an abductive context (cf. Sonesson 1989a, I.2).

Piaget's notion of differentiation is vague, and in fact multiply ambiguous, but, on the basis of his examples, two interpretations can be introduced (cf. Sonesson 1992a; 1992b; 1995b): first, it might correspond to the sign user's idea of the items pertaining to different basic categories of the common sense Lifeworld; and, in the second place, it could refer to the impossibility of one of the items going over into the other, following the flow of time or an extension in space. Indeed, it is sufficient to catch a glimpse of the wood-cutter lifting his axe over his shoulder and head to know what has gone before and what is to come:

25 About proper parts, perceptual perspectives, and attributes as different ways of dividing an object and thus different indexicalities, cf. Sonesson 1989a, I.2. 
that he has just raised his tool from some base level, and that at the next moment, he is going to hit the trunk of the tree. Here the flow of indexicalities is only momentarily halted. Whereas the items forming the sign are conceived to be clearly differentiated entities, and indeed as pertaining to different "realms" of reality, the "mental" and the "physical" in terms of naïve consciousness, the items of the perceptual context continuously flow into each other, and are not felt to be different in nature. $^{26}$

The concept of semiotic function, which has here been developed from a reading of Piaget, is not the same as the one found in the work of Hjelmslev, who uses it to distinguish signs from what he calls "symbol systems": the former, but not the latter, require a different analysis into minimal units on the levels of expression and content, that is, they have “double articulation" (cf. Sonesson 1992a; 1992b). In Hjelmslev's view, not only chess and other games as well as mathematical symbols but also pictures and onomatopoeias form symbol systems. ${ }^{27}$ There are many reasons to doubt this analysis: other criteria than the linguistic ones may be found which will allow for a distinct articulation of expression and content (as I have suggested above), and the content and expression of onomatopoeias are certainly different also according to linguistic criteria. But in any case, both onomatopoeias and pictures are differentiated according to our criteria, because expression and content are clearly experienced as being of different nature and having separate spatial and/or temporal location.

Differentiation is also different from "displacement", which, in Hockett's (1977) classical formulation, is one of the "design features" of human language: the capacity for being used to refer to things remote in time and space. No doubt this is an important property of some signs, and it has even been suggested that the necessity of remembering the past and of planning for the future (displacement in time) is at the origin of human language (Sjölander 2002; Deacon 1997: 397ff). If so, this property is also realised by pictures as well as by some gestures. Inter-

26 In fact, both content and expression of the sign are actually "mental" or, perhaps better, "intersubjective", as structural linguists would insist; but we are interested in the respect in which the sign user conceives them to be different.

27 Actually, Hjelmslev may not be talking about pictures as such, because he literally claims that "The Christ of Thorvaldsen as a symbol of compassion" is a symbol. But even this could be disputed applying our criteria. It will be noted that the distinction between sign and symbol in Hjelmslev's work is quite different both from the Peircean and the Saussurean tradition. 
estingly, however, other gestures (such as, most notably, pointing), which, on our criteria, are clearly signs, do only function as they do in the presence of the object to which they refer (cf. Sonesson 1995b). A large portion of verbal signs, and not only what has variously been called (with only partly overlapping terms) "deictics", "egocentric particulars", "shifters", etc., accomplish their peculiar function in the presence of their referent. Indeed, even some pictures require the presence of the referent. In the zoo, for instance, both the verbal label and the picture of the animal will only function as they are meant to function helping us applying the right name to the animal - in presence of the animal referred to (cf. Sonesson 2003; 2004). So while the capacity of language and pictures for functioning in the absence of their referents is important, it may be equally important that they have usages in the presence of their referents.

In fact, the sign, and therefore differentiation, may be necessary for a much wider purpose: to single out different portions of the perceptual world for attention. Within semiotics, Prieto (1966; 1975a; 1975b) has long insisted on the importance of this function of signs. Interestingly, also Tomasello (1999: 131ff) has recently arrived at the same conclusion: the basic function of "symbolic representation" is "attention manipulation", which, beyond "displacement", "undermines the whole concept of a perceptual situation by layering on top of it the multitudinous perspectives that are communicatively possible for those of us who share the symbol". ${ }^{28}$ As we shall see (in the second part), this actually points to a more elementary sense of meaning, which, in different traditions, is called such things as "relevance", "pertinence", or "form". It is at the origin of the Peircean concept of "ground".

Deacon (1997: 397), however, suggests that "almost any objects or events or even particular qualities of objects or events can be signified without symbolic reference, using iconic or indexical means". It is difficult not to be reminded of Swift's scholars who communicated using objects, which they carried with them. The difficulty with this solution is not only that one cannot carry all conceivable objects on one's back

\footnotetext{
28 It is not clear to me whether the perspective mentioned here should be viewed in relation to similar ideas of Bakhtin's, for Tomasello's quotes from the latter concern other issues. Interestingly, however, Bakhtin allows for such perspectives being incorporated into drawings, as well as into linguistic signs, but denies their presence in photographs, for reasons that I have shown to be erroneous. Cf. Sonesson 1999; 2001a.
} 
(which would be equivalent to the displacement argument), but also that the properties and relationships between these objects cannot be manipulated freely (which is the argument from relevance). In some respects, this is similar to Deacon's own claim, that "nonsymbolic reference" cannot point to "abstract or otherwise intangible objects of reference" (ibid.), but the latter may be too general a formulation because it does not mention the possibility of changing the principles of relevance. The latter, in any case, is a capacity of pictures and some gestures as well as verbal language.

It cannot be denied, however, that in some respects my interpretation of Piaget goes against his own self-understanding. I have made much out of a distinction between the "objective" and the "subjective point of view" (which is precisely a kind of "attention manipulation"), which Piaget introduces only later to forget all about it himself. Indeed, if we look at Piaget's examples, it seems that he attributes the semiotic function only to those expressions and contents which are not only subjectively, but objectively different: the pebble in relation to the candy, but not the feather in relation to the bird. ${ }^{29}$ In other terms, he seems to confuse differentiation, in the end, with symbolicity, that is, the arbitrariness that accounts for the connection between the expression and the content.

Interestingly, this is, at least by implication, the same confusion we discover in Deacon's work: to him that "special kind of reference" we find in symbols, and notably in verbal language, seems to involve a lack of motivation, opposed to the motivated relationships appearing in icons and indices; but it is, at the same time, as his examples show, differentiation as opposed to non-differentiation. The evaluation of Deacon's claim is certainly complicated, as we shall see, by his rather curious interpretations of iconicity and indexicality, and by his attribution of a system character to all instances of symbolicity (which perhaps, in the end, rather than arbitrariness, is that which defines symbols to Deacon). But clearly, when it comes to the attribution of sign status to the vervet monkey alarm calls, the question at issue is not whether the monkeys perceive contiguities and/or similarities between the calls and the

\footnotetext{
29 A passage from Deacon (1997: 413f) which seems to go in the direction of my distinction, is when he opposes the "indexical" interpretation of the chimpanzees which are unable to choose the small heap of candies, although they have observed that as a result they are given the big heap, to the "symbolic" interpretation of children who are able to learn the adequate reaction.
} 
predators, but whether they see the former as being anything else than a part of the situation which also contains the latter.

There can be no doubt that the identification of differentiation with symbolicity is a serious confusion, at least because it makes it impossible to formulate some relevant questions for research. And one of the questions which our terminology permit us to formulate actually may explain why both Piaget and Deacon have been led down this alley: it is conceivable that, phylogenetically as well as ontogenetically, differentiation can first only be experienced on the basis of symbolicity, and is then later generalised to iconic and indexical relationships. At this stage, obviously, this can only be a speculative proposition.

On the other hand, it is possible that the notion of differentiation, as it is used here to define the concept of sign, itself needs interpretation. Tomasello's (1997) claims that the sociocultural contexts in which humans are reared allow them, contrary to other animals, to develop "joint attention", which permits them to discover the goals and motives behind the actions of others. This idea is intriguing, particularly in view of the parallelism which Tomasello, along with Vygotsky (and, unknowingly to him, Prieto), postulates between tools and signs. Both tools and signs point beyond themselves, Tomasello notes, to the problems they are set to resolve, and to the situation they describe, respectively. Prieto would say that a set of expressions is connected to a set of contents, just as a set of tools relates to a set of usages. ${ }^{30}$ Just as Tomasello talks about taking different perspectives, Prieto insists on the set of alternatives (known in classical structuralist semiotics as "paradigm"). In both tools and signs, it seems necessary to intercalate an intention between the two sets, in order to explain the possibilities of choice. To Prieto, who looks at the issue from a more theoretical point of view, intentionality is an additional message, which is superimposed on the original sign. To Tomasello, on the other hand, intentionality is at the origin of all signs, because causality is a later reinterpretation of what was originally a magically misunderstood intentionality, attributing goals to the things of the natural world. ${ }^{31}$

30 Elsewhere, I have introduced the term allofunctionality to characterise objects that are defined by reference to the properties of other objects, such as tools and signs (cf. Sonesson 1989a).

31 The case of autism is very interesting, because Tomasello interprets it in the sense of a failure to see others as conscious beings, and thus to entertain joint attentions with them. We know however, from other sources (see Winner 1982: 
Seen in this way, the semiotic function seems to have something to do with mediation, not only in the very general sense of Peirce and Vygotsky, but in the more special sense of second generation behaviourist theories: an intercalated variable between stimulus and response. Here again, we are of course at the level of mere speculation.

\subsection{The picture as a sign.}

On not seeing the depiction owing to all the paper

The picture is a sign, in the sense of it having a signifier which is doubly differentiated from its signified, and which is non-thematic and directly given, while the signified is thematic and only indirectly present. This also applies to rock paintings and rock carvings: the rock itself is made of quite another material than the arms, the elks, the boats, and the human beings depicted; indeed, even those stone implements which are represented are not rendered in the same material, since the expressions of these contents are not really the rock itself, but the carved hollows, and the pigment lines, made in, or on, the rock. Nor is there any continuity in space and time between the motifs and their rendering. The rock and its carvings, as well as the pigments deposited upon it, are directly given to our perception; that which is thematic, however, are the animals, men, arms, and tools suggested by these means.

The perception of surfaces is important for the possibilities of survival of all animals; it is only by means of determining their mutual relations that the animals are capable of orienting themselves in the world of experience. However, according to James Gibson (1980), it is only to human beings that the marks made on surfaces attract attention. Such marks may be of different types, for example, colour spots, lines or projected shadows; and they can be produced in different ways: by the fingers, with a pencil, a brush, some engraving instrument, with a rule, a

$181 \mathrm{ff})$ that some autistic children a better than normal children at some specific tasks, which include such things as "photographic memory", the ability to sing an entire opera after hearing it once, and an extraordinary capacity for drawing. Just as in the other cases mentioned, however, the drawing ability is of the kind permitting a very close reproduction in the expression of the content as given, without any apparent awareness of alternatives. In this sense, expression and content here appear to be imperfectly differentiated. It is intriguing however, that this is exactly the opposite of the kind of drawing chimpanzees have been known to accomplish. 
compass, or with a more complex instrument such as a printing-press, a camera or a projector. The marks on the surface can be disorderly and may even be dirt spots. If they are symmetrical or regular in some way, they make up some kind of ornament; but if the marks have a form that can be interpreted as referring to a possible perceptual scene, we have to do with a picture.

If we follow Gibson, the capacity to interpret pictures is as unique a human capacity as that of using verbal signs. This contention may appear to be contradicted by numerous experiments which show that some animals react to pictures of their keeper in the same way as to the keeper himself; this notably appears to be true of pigeons (cf. Cabe 1980; Fagot 2000). However, these experiments do not show to what extent the animals perceive the pictures are something different from a new instance of the human being in person. In this sense, the iconicity of pictures, to human beings at least, is very different from Deacon's (1997: 76) description of "seeing just more of the same (bark, bark, bark...)." Julian Hochberg showed that a child 19 months old who had never seen a picture could readily interpret it if he/she were familiar with the objects depicted (Hochberg, Brooks 1962). But Hochberg did not investigate whether the child saw the picture as a picture or as an instance of the category of the depicted object - a picture of a bird as a bird, etc. For the picture to be a sign, both similarity and difference have to be involved.

Recent experiments have shown that even children 5 months old look longer at a doll than at its picture (DeLoache, Burns 1994). However, it does not follow that the children see the picture as a picture. Indeed, 9th month olds, but not 18th month olds, try to grasp the object depicted as if it were a real object (DeLoache 2004); whatever the difference they perceive, then, it does not seem to involve signs as opposed to objects. Just as in the case of the doves, this may simply show that the picture and its object are seen as different, but not necessarily as being a sign-vehicle and its referent. The real doll is perhaps seen as a more prototypical instance of the category; or, alternatively, the real object may be more interesting because of having more perceptual predicates.

Once we know that something is a sign, and, specifically, a pictorial sign, the particular "similarities" will take care of themselves. If we are not told that some particular thing is a sign, and iconic at that, then we may perhaps be aware of it because of general facts derived from our 
experience of the common sense world. Members of the Me' tribe, we are told, smell the pictures, taste them, bend them, and so on, in short behave like a Piagetian child exploring his world. According to Deregowski (1973: 167; 1976: 20) not only pictures, but materials like paper are unknown to the Me'; therefore, when Deregowski had pictures printed on coarse cloth, animals well-known to the tribe could be identified, although the recognition was still not immediate. It appears the Me' were so busy trying to discover the fundamental properties of the paper as an object in itself, that the iconic properties, those making it a pictorial sign of something else, were not noted; other attributes became dominant in their experience of it. It therefore seems (as I suggested in Sonesson 1989a) that for something to be a pictorial sign of something else, it must occupy some relatively low position in the particular Lifeworld hierarchy of "things".

If we suppose the Hochbergian child to understand, not only that given pigment patterns on paper have something to do with the shoe, the doll, and the Volkswagen of the real world, but also that the former are signs for the latter, and not the reverse, then it will not be enough for the child to have learnt from his experience with objects of the world that the edges of objects have properties which are shared by contours drawn on paper, or to be innately predisposed to react to these common properties (cf. Hochberg 1978: 136; cf. 1972). He must also have acquired, probably from experience in his particular Occidental Lifeworld, some notion of the relative low ranking on the scale of prototypical Lifeworld things of a material like paper, which directs his attention, not to what the pigment patterns on the paper are as "selves", but to what they stand for. And perhaps he must also possess some idea of a meaningful organisation, which relieves him of the task of finding a meaning in inkblots, in the dirt on the road, in the stains he makes with his dinner on the tablecloth and in the clouds.

Familiarity with paper and familiarity with cloth are facts of particular cultures. Paper, which is too prominent to the Me' to serve as a sign-vehicle, traditionally carries this function in Western culture. But there would probably also be universals of prominence: thus, for instance, two-dimensional objects are felt to be less prominent than threedimensional ones and may thus more readily serve as expressions. In this sense, it is not true that the object is its own best icon, as is ordinarily claimed - at least if iconic means iconic sign. Indeed, iconicity stands in the way of the sign function. The objects of the common sense 
world are three-dimensional: much less is required for a twodimensional object than for another three-dimensional object to represent one of these objects. This is precisely what is suggested by DeLoache's more recent experiments with children: not only is the picture understood later than language in these experiments, around $21 / 2$ years (DeLoache, Burns 1994; etc.), but scale models are understood even later, at 3 years of age, half a year after pictures (DeLoache 2000). As noted also by DeLoache, this contradicts what is expected by common sense. But it is reasonable, if the issue is separating the sign and its referent.

DeLoache (2004) employs the term "double representation" to describe the necessity for the child to attend both to the picture and the object depicted. This is a misleading term, for there is only one representation, that is, one sign function. ${ }^{32}$ Rather, in Gibson's more enlightening terms, there are invariants for both the surface and the referent in the object, and the task is to tell them apart, and decide which is most prominent. In fact, the problem only arises because there is at the same time sign function and iconicity. This means that the term "double representation" is not only misleading: if fails to explain why pictures are easier to interpret than scale models.

In all DeLoache's experiments, the task is, in one way or other, to find a hidden object by using information contained in a picture or a scale model. According to the standard procedure, the experimenter and the child are outside the room in which the child is to search for the toy. The child cannot see the picture/scale model and the room at the same time. The experimenter tells the child that she will hide the toy in the room and then come back and ask the child to search for it. She returns to the child and points out the appropriate location in the picture/scale model telling him "This is where Snoopy is hiding in his room, can you find him?". If the subject fails in the first search it is once more shown the picture and given more explicit prompts. 24 month old do not pass the retrieval test, but 30 month old do; there is no difference in performance using photographs or line drawings. However, when the whole procedure is conducted verbally, children pass the test already before 24 months old; and when a scale model is used, only 36 months old pass it.

32 Perhaps DeLoache talks about "representation" in the sense in which the term is often used in cognitive science, but then this is precisely the problem, as we have suggested above. 
This way of investigating the picture function may be criticised from two diametrically opposed points of view. First, it could be argued that the task involves much more than the recognition of the picture as picture - it requires an action, which is no doubt difficult in itself, namely, to search for the hidden object. It remains, however, that even this task is differently accomplished if the instructions are given in entirely verbal form, or if they involve pictures or scale models. On the other hand, even when the instructions for the task feature pictures or scale models, at lot of verbal and indexical scaffolding also takes place, without this being taken into account in the interpretation. It has been argued by Callaghan and Rankin (2002) that pictures would be interpreted even later if such verbal scaffolding had not taken place. More fundamental, however, may very well be the indexical scaffolding: not only are the objects pointed out by the experimenter in the picture or the scale model, but the latter are even placed on the real objects, creating an artificial neighbourhood relation.

Another one of DeLoache's experiment seems to indicate that the sign function is at least part of the problem. When the experimenter, instead of talking about a model and a real room, tells the children that the search has to take place in the same room, which has shrunken since it was last seen, the task is accomplished much more easily (DeLoache et al. 1997). The difference, clearly, is that the two instances are here connected by a narrative chain rather than by a sign relationship. In another experiment, DeLoache (2000) places the scale model behind a window-pane, in order to make it more similar to a picture, with the expected results. In fact, however, two things happen here which would have to be separated: the object becomes less prominent, because it has less the appearance of three-dimensionality; and it is put into a frame, which creates a centre of attention.

DeLoache's work experimentally investigates the central issues broached in Sonesson (1989a). ${ }^{33}$ As always, the investigation engenders new problems. However, if understanding pictures is as difficult for children as DeLoache and, even more, Callaghan, suggest, then we should not expect animals to be able to do so. We have already proposed some alternative explanations for the behaviour of Cave's pigeons. On the other hand, primatologists, as mentioned at the beginning of this section, tend to take for granted that the apes to which they are trying to teach language already understand pictures. There are only a

33 Clearly without knowing Sonesson 1989a. 
few regular investigations of apes looking at pictures and scale models. Itakura (1994) reports that enculturated chimpanzees can interpret line drawings; Kuhlmeier et al. (1999; Kuhlmeier, Boysen 2001; 2002) have even shown their chimpanzees to understand scale models. It is difficult to know what to make of these results, already because these apes are all enculturated, which is to say that they are trained in many of the semiotic resources that in ordinary circumstances are peculiar to the human Lifeworld. Moreover, it should be noted that, while the children were introduced to a model of a room that they had never seen before the training-phase, the apes were confronted with a model of their own familiar environment. In addition, a lot of facts about the subjects and the experimental procedure are not clear from the articles. At present, it would therefore be premature to draw any conclusions about the abilities of the great apes in this domain.

It is clear, however, that, in order to understand the peculiarity of the picture, we need a concept of sign which can account for the difference and similarity between perception and pictures, on the one hand, and of pictures and scale models on the other.

\subsection{Beyond the "fleeting instant".}

From iconicity to the iconical sign

Deacon's way of using the Peircean notions of iconicity and indexicality is curious, not only in relation to the naïve interpretation, found in many textbooks, but also, I am afraid, with reference to a deeper reading, which takes into account the underlying armature of Peircean philosophy. As I have repeatedly pointed out, I am not particularly interested in opposing an orthodox interpretation of Peirce to the one realised by Deacon. What does interest me is to find a more enlightening way of talking about the complexities of semiosis.

Deacon (1997: 70f) starts out rather cautiously, pointing out that terms like icon, index and symbol have been used in other senses by scholars before and after Peirce. In his view, however, Peirce was involved in investigating "the nature of the formal relationship between the characteristics of the sign token and those of the physical object represented", where icons depend on similarity, indices on "some physical or temporal connection", and symbols on "some formal or merely agreed-upon link". He also relates Peirce's three sign types to the classical repertory of associa- 
tions types, which he lists as: "a) similarity, b) contiguity or correlation; c) law, causality, or convention". This seems compatible with many passages in Peirce's work, with the exception that causality would be in the second category. Deacon no doubt is aware of this, because already on the following page he talks about indices being "causally linked to something else".

Deacon (1997: 71f) also quite correctly observes that nothing is an icon in itself, and that similarity is not "caused" by iconicity. "What we usually mean is that they were designed to be interpreted that way, or are highly likely to be interpreted in that way." 34 However, we need the Peircean notion of ground to account for this fact. As we shall see, an object is actually iconic in itself, but it is only an iconic ground in relation to something else, and an iconic sign in relation to a further relation. Deacon rightly notes that something, such as (a sign of) American Sign Language (ASL), may well partake of different sign types, such as iconicity and symbolicity, at the same time. He is wrong, however, in identifying iconicity with depiction, that is perceptual resemblance. More importantly, perhaps, he fails to note that this shows that the Peircean sign categories are not types of signs at all, but types of relationships between the parts of a sign. ${ }^{35}$

So far, this is a somewhat more subtle reading of the "received version" of Peirce's theory. Where Deacon's (1997: 74ff) interpretations become strange, however, in when he suggests that iconicity is the fact of there being no distinction: the perception of the same "stuff" over and over again. It is, he maintains, like camouflage: the moth's wings being seen by the bird as "just more tree". Deacon (1997: 77ff) goes on to sug-

34 This hardly seems compatible with Figure 2.2. in Deacon's book, in which symbols are said to have an "opaque" relationship to their object, and icons a "transparent" one, which is glossed as "that they require no additional knowledge to 'see' the one through experience of the other" (Deacon 1997: 60).

35 Deacon (1997: 72ff) goes on to discuss Peirce's idea according to which an index always contains an icon, and a symbol an index, which he interprets in the sense that the capacity to interpret icons must precede the ability to understand indices, and the ability to make sense of indices must come before that of making use of symbols. This is probably not what Peirce meant. In any case, it is certain that the child first is able to interpret the marks on a paper as indices (traces of its own movements), then as icons or symbols (depictions or letters). In another sense, it can be shown that some indices contain icons, such as the footprint, which is an imprint of a foot, but also resembles it, but that others fail to do that, such as the pointing finger, which has no similarity with what it indicates. Cf. Sonesson 1989b; 1999; 2001b; 2001c. 
gest that iconicity is recognition, that is, the identification of a category, and even "stimulus generalisation". Interestingly, he is quite right, from a Peircean point of view, in searching for a "basic sense" of iconicity beyond "the way we typically use the term", but he is looking in the wrong place: what he comes up with is both too much and too little, as we shall see when we attend to the notion of Firstness. Deacon (1997: 76f) then claims that "typical cases" such as pictures are essentially of the same kind: what makes pictures into icons is "the facet or stage that is the same for a sketch and the face it portrays". Curiously, he then refers to Peirce's saying that, upon closer inspection, an icon can convey further information about its object, and quotes "the simplification in a diagram or the exaggeration in a cartoon" as instances of this. Although Peirce may really have meant something rather akin to Deacon's claim, the latter examples clearly point in the opposite direction: they show that a difference between the sign and its referent is needed to convey new information.

In Peircean parlance, to put it simply (but we will later see that this is all too simple a manner of putting it), an icon is a sign in which the "thing" serving as expression in one respect or another is similar to, or shares properties with, another "thing", which serves as its content. In fact, according to Peirce, there are two further requirements: not only should the relation connecting the two "things" exist independently of the sign relation, just as in the case of the index, but, in addition, the properties of the two "things" should inhere in them independently. ${ }^{36}$

36 We are of course not concerned with pictorial representations of persons or events derived from the sacred history of Christianity, often used as an aid to devotion. Icons in the religious sense are not particularly good instances of icons in the semiotical sense, for they are, as Uspenskij (1976) has shown, subject to several conventions determining the kind of perspective which may be employed, and the kind of things and persons which may be represented in different parts of the picture. It may be less clear that the term is not to be used to refer to all things visible, or to everything whose elements are graphically disposed, as in the jargon of computer programming, or in cognitive psychology (e.g. Kolers 1977). Contrary to the latter usage, iconic signs may occur in all sense modalities, e.g. in the auditive modality, notably in verbal language (not only onomatopoetic words, but also in the form of such regularities and symmetries which Jakobson 1965a, b terms "the poetry of grammar") and music (cf. Osmond-Smith 1972), and not all visual signs are iconic in the semiotic sense; indeed, many icons found in computer programs are actually aniconic visual signs. Curiously, many semioticians also tend to confuse these two quite different senses attributed to the term "iconicity": thus still in Eco 1999: 100, in spite of admitting his error in Eco 1998: 10; 
Contrary to what is suggested by Groupe $\mu$ 's (1992) quotation from Dubois' dictionary, iconicity, in the Peircean sense, is thus not limited to a resemblance with the external world ("avec la réalité extérieure'). When conceiving iconicity as engendering a "referential illusion" and as forming a stage in the generation of "figurative" meaning out of the abstract base structure, Greimas and Courtés (1979: 148, 177) similarly identify iconicity with perceptual appearance. In fact, however, not only is iconicity not particularly concerned with "optical illusion" or "realistic rendering", but it does not necessarily involve perceptual predicates: many of Peirce's examples have to do with mathematical formulae, and even the fact of being American, as in the Franklin and Rumford example, is not really perceptual, even though some of its manifestations may be (cf. Sonesson 1989a: 204ff; 1996; 1998a; 2000a; 2001b; 2001c). It is also common to confound iconicity and picturehood, when in actual fact, if we rely on Peirce's definition, pictures constitute only one variety of iconicity and are not even supposed to form the best instances of it. Something additional in necessary to account for the pictorality of pictures, as I have shown elsewhere (cf. Sonesson 1989a; 1989b; 2001c; 2003; 2004; in press a, b, c). Contrary to what Deacon (1997: 72) seems to imply, the signs of ASL, just like those of Blissymbolics and some kinds of gesture, which I have discussed in another context (cf. Sonesson 2001b), may well rely in part on an abstract type of iconicity which is distinct from depiction.

During the second half of the last century, the claim that there can be no iconic signs came from two rather different quarters. Philosophers like Bierman (1963) and Goodman (1968; 1970), only the first of whom explicitly refers to Peirce, started out from logical considerations, together with a set of proto-ethnological anecdotes, according to which so-called primitive tribes were incapable of interpreting pictures; outright semioticians such as Eco and Lindekens, on the other hand, wanted to show that pictures conformed to the ideal of the perfect sign, as announced by Saussure, by being as arbitrary or conventional as the sign studied by the "most advanced" of the semiotic sciences, general linguistics. Since then, the question has largely gone out of fashion, but the results of those disquisitions have, rather undeservedly, been taken for granted by later researchers. In my own work on iconicity, which dates from the period of low tide in the debate (Sonesson 1989a; 1992a;

1999: 340. For further details of this analysis of iconicity, see, notably, Sonesson 1989a; 1993; 1994; 1995a; 1996; 1998a; 2000a; 2001b; 2001c. 
1992b; 1993; 1994; 1995a; 1996; 1998a; 2000a). I have quoted evidence from psychology and ethnology that tends to show that that conclusion is unfeasible. More importantly, however, I have also suggested that the arguments against iconicity were mistaken, mainly because they construed language and pictures, as well as the world of our experience, i.e. the Lifeworld, in a fashion which is incompatible with our empirical knowledge, i.e. with that which we have good reasons to believe to be true about the world.

If iconicity is part of a (ternary) structure, then it cannot be discussed outside the framework of Peirce's division of signs into icons, indices, and symbols. ${ }^{37}$ Within philosophy, many divisions of signs have preceded the one proposed by Peirce, ending up with two, or four, or more categories. In some ways, these divisions may be more justified than the Peircean one. However, quite apart form Deacon's reference to Peirce, there are two reasons for taking our point of departure in the Peircean canon: first, it is within these frames that most of the discussion has been conducted; and secondly, when we look beyond those elements which have usually been addressed in the discussion within semiotics, we will find that Peirce's theory offers some help for developing a more subtle approach to iconicity. Even though we may not find the Peircean categories of Firstness, Secondness, and Thirdness particularly useful for the understanding of the Lifeworld, they are important for grasping the differences between his sign types. Indeed, one should never forget that icons manifest Firstness, indices Secondness, and symbols Thirdness.

Many semioticians, in particular those who deny the existence of iconic signs, apparently believe pictures to be typical instances of this category. There are several reasons to think that this was not Peirce's view. Pure icons, he states (1.157), only appear in thinking, if ever. According to Peirce's conception, a painting is in fact largely conventional, or "symbolic". Indeed, it is only for a fleeting instant, "when we lose consciousness that it is not the thing, the distinction of the real and the copy", that a painting may appear to be a pure icon (3.362; cf. Sonesson 1989a, III.1). It will be noted, then, that a pure icon is thus not a sign, in the sense

37 The Peircean use of the term "symbol" is of course problematic, since it contrasts with another sense, more common in the European tradition, and which is found for instance in the work of Saussure, where it is a particular kind of icon. However, it appears that "conventional sign" is not an adequate term for what Peirce means by "symbol", which may involve "law-like" relationships of other kinds (perhaps those which are observed to obtain). 
of the semiotic function discussed above (although Peirce will sometimes state the contrary). At first, it may seem that although the icon is not a socially instituted sign, i.e. not something which is accepted by a community of sign uses, it could at least, for a short time span, become a sign to a single observer. But even this is contrary to the very conditions described by Peirce: he specifically refers to the case in which the sign loses its sign character, when it is not seen as a sign but is confused with reality itself (which could actually happen when looking at a picture through a key hole with a single eye, producing what Husserl dismisses as a "Jahrmakteffekte"), when, as Piaget would have said, there is no differentiation between expression and content (cf. Sonesson 1989a, I.2.5; 1992b).

Indeed, it would seem that, at least sometimes, the pure icon is taken to be something even less substantial: an impression of reality, which does not necessarily correspond to anything in the real world, for "it affords no assurance that there is any such thing in nature" (4.447). Thus, it seems to be very close to the "phaneron", the unit of Peircean phenomenology (itself close to the Husserlean "noema"), which is anything appearing to the mind, irrespective of its reality status (cf. Johansen 1993: 94ff). In this sense, the Peircean icon is somewhat similar to that of cognitive psychology, for it involves "sensible objects" (4.447), not signs in any precise sense: however, it comprises all sense modalities.

Now it may seem that iconicity, characterised in this way, corresponds rather well to Deacon's (1997: 74ff) description of not making a distinction, of "just more tree", "bark, bark, bark..." or "stuff, stuff, stuff...". The most obvious objection to this is that there does not appear to be any difficulty in thinking any of these things (even if the bird may not think it, in our sense of thinking), as Peirce suggests should be the case with a pure icon. More importantly, however, these are all relational statements, and whatever else Firstness means, it certainly conveys up a world (or, more exactly, a view of the world) deprived of all relations. The contradiction becomes even more patent, when Deacon (1997: 77ff, 300f) identifies iconicity with recognition and category membership, both of which suppose relations, as much no doubt as "compound iconic analysis" (my italics). This is the sense in which Deacon's interpretation of iconicity allows too much. But it is also too little: the iconic sign is a bundle of relations.

To go from the concept of iconicity to the iconic sign, we have to ponder the meaning of a notion, sporadically, but often significantly, used by Peirce, i.e. the notion of ground. As applied to signs, I will here 
suppose, iconicity is one of the three relationships in which a representamen (expression) may stand to its object (content or referent) and which can be taken as the "ground" for their forming a sign ${ }^{38}$ : more precisely, it is the first kind of these relationships, termed Firstness, "the idea of that which is such as it is regardless of anything else" (5.66), as it applies to the relation in question. In one of his well-known definitions of the sign, a term which he here, as so often, uses to mean the sign-vehicle, Peirce (2.228) describes it as something which "stands for that object not in all respects, but in reference to a sort of idea, which I have sometimes called the ground of the representamen" (Fig. 1).

According to one of Peirce commentators, Greenlee (1973: 64), the ground is that aspect of the referent, which is referred to by the expression, for instance, the direction of the wind, which is the only property of the referential object "the wind" of which the weathercock informs us. On the other hand, Savan (1976: 10) considers the ground to consist of the features picked out from the thing serving as expression, which, to extend Greenlee's example, would include those properties of the weathercock permitting it to react to the wind, but not, for instance, its having the characteristic shape of a cock made out of iron and placed on a church steeple. It seems to me that, in order to make sense of Peirce theory, we must admit that both Greenlee and Savan are right: the ground involves both expression and content. Rather than being simply a "potential sign-vehicle" (Bruss 1978: 87), the ground would then be a potential sign. Such an interpretation seems to be born out by Peirce's claim that the concept of "ground" is indispensable, "because we cannot comprehend an agreement of two things, except as an agreement in some respect" ( $C P$ 1.551).

38 It should be noted that I will be avoiding peculiarly Peircean terms in the following, as long as no harm is done by that procedure: I will use "expression" for what Peirce calls "representamen" and "content" for his "object": more precisely, I will roughly identify "immediate object" with "content" and "dynamical object" with "referent", though it might have been better to say that the "immediate object" is what is picked out of the "dynamical object" by the ground. For the purpose of this article, I will dwell as little as possible on the "interpretant", which is clearly also a part of meaning, though not in the simple way suggested by Ogden's and Richard's all too familiar triangle. In many of my earlier works, I have argued for a relationship between the ground and the interpretant, and Johansen (1993: 90ff) even claims the latter was historically substituted for the former, but I now think the relationship cannot be that straightforward, for reasons which will partially appear below. 


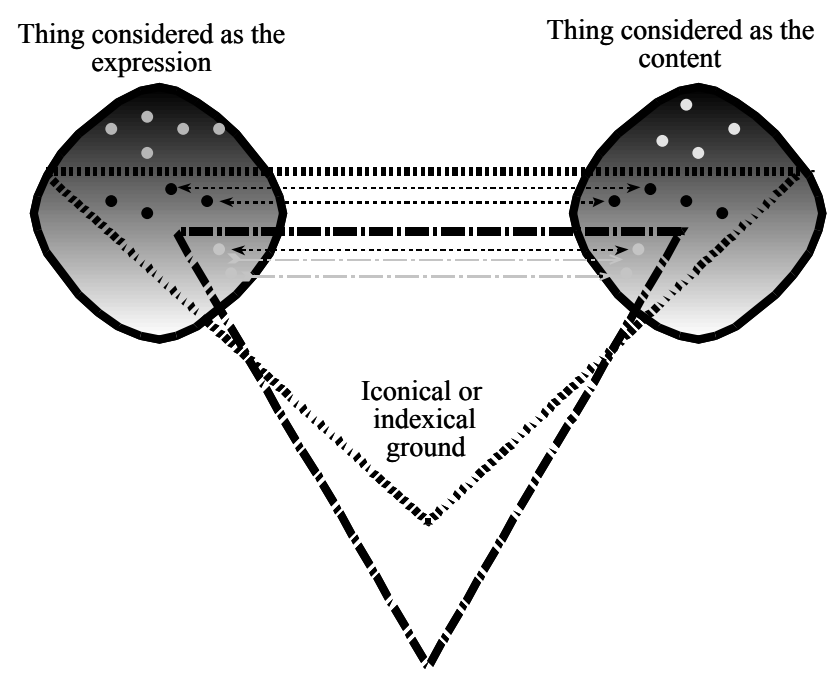

Semiotical or sign function

Fig. 1. The sign as a mapping between different spaces, based on different principles of relevance, iconical and/or indexical ground and the sign function. The points are properties of the two things thus put into relation. The arrows are mappings between such properties.

In another passage, Peirce himself identifies "ground" with "abstraction" exemplifying it with the blackness of two black things ( $C P 1.293)$. It therefore seems that the term ground must stand for those properties of the two things entering into the sign function by means of which they get connected. i.e. both some properties of the thing serving as expression and some properties of the thing serving as content. In case of the weathercock, for instance, which serves to indicate the direction of the wind, the content ground merely consists of this direction, to the exclusion of all other properties of the wind, and its expression ground is only those properties which makes it turn in the direction of the wind, not, for instance, the fact of its being made of iron and resembling a cock (the latter is a property by means of which it enters an iconic ground, different from the indexical ground making it signify the wind). If so, the ground is really a principle of relevance, or, as a Saussurean would say, the "form" connecting expression and content: that which must necessarily be present in the expression for it to be related to a particular content rather than another, and vice-versa (cf. Sonesson 1989a, III.1). 
If the ground is a form of abstraction, as Peirce explicitly says, then it is a procedure for engendering types, at least in the general sense of ignoring some properties of things and emphasising others, for the purpose of placing them into the same class of things. ${ }^{39}$ And if it serves to relate two things ("two black things" for example, or "the agreement of two things" in general), it is a relation, and it is thus of the order of Secondness, i.e. "the conception of being relative to, the conception of reaction with, something else" (CP 6.32). All this serves to underline the parallel with the principle of relevance, or pertinence, which is at the basis of structural linguistics, and the semiotics inspired by it (Hjelmslev and Prieto, notably). But we could take this idea further, adding to the notion of ground a more explicitly constructive aspect. To many structuralists (the Prague school notably), relevance is a double movement, which both serves to downplay non-essential elements and to add others which were anticipated but not perceived: thus, it depends on the twin principles of "abstractive relevance" and "apperceptive supplementation" embodied in Bühler's Organon model (cf. Sonesson 1989a, II.4.2), as well as in the Piagetean dialectic between accommodation and assimilation (cf. Sonesson 1988, I.3.1). Perhaps Peirce himself later abandoned the notion of ground because of its rather static-sounding character. ${ }^{40}$ Interestingly, above I was led to describe what was going on, as "a procedure for engendering types", as a "double movement" from abstractive relevance to apperceptive supplementation", and as a "Piagetean dialectic between accommodation and assimilation". So in spite of the name, it seems we are concerned with a constructive device. Unfortunately, Peirce never gave another name to this phenomenon. Perhaps we should call in "grounding" (if we had not already have had to pay it extra for all the tasks we have given it, as Humpty Dumpty would have said).

Given these preliminaries, it might be said that an indexical ground, or an indexicality, involves two "things" that are apt to enter, in the

\footnotetext{
39 In this sense, the model presented here (and already in Sonesson 1989a), is similar to that independently proposed by Groupe $\mu$ (1992: 124-156; 1995); since both are based on the notion of types mediating between similar predicates, except for the fact that Groupe $\mu$ postulates a type only on the side of content. Although Peirce does not specify his terms here, it seems that we are concerned with abstraction in both those senses which Peirce later takes great care to distinguish, the selection of properties ("creating predicates"), and the process of nominalisation ("creating subjects"; cf. Stjernfelt 2001).

40 As was suggested to me by John Michael Krois.
} 
parts of expression and content ("representamen" and "object" in Peircean parlance), into a semiotic relation forming an indexical sign, due to a set of properties which are intrinsic to the relationship between them, such as is the case independently of the sign relation. ${ }^{41}$ Indexicality, which is a ground, and therefore a relation, is thus basically different from iconicity, which consists of a set of two classes of properties ascribed to two different "things", which are taken to possess the properties in question independently, not only of the sign relation, but of each other, although, when considered from a particular point of view, these two sets of properties will appear to be identical or similar to each other. This is the sense in which indexicality is Secondness, and iconicity Firstness. As for the Peircean symbol, or generic sign, it is literally groundless, at least until it becomes a sign: there is nothing in the thing serving as expression, nor the thing serving as content which explains the sign relation. The principle of relevance obtaining between the two parts of the sign is produced merely by the sign relation, which is why it is Thirdness (cf. Fig. 2). ${ }^{42}$

\begin{tabular}{|l|l|l|l|}
\cline { 2 - 4 } \multicolumn{1}{c|}{} & $\begin{array}{l}\text { Firstness } \\
\text { Impression }\end{array}$ & $\begin{array}{l}\text { Secondness } \\
\text { Relation }\end{array}$ & $\begin{array}{l}\text { Thirdness } \\
\text { Habituation/Rule }\end{array}$ \\
\hline $\begin{array}{l}\text { Firstness: } \\
\text { Principle }\end{array}$ & Iconicity & - & - \\
\hline $\begin{array}{l}\text { Secondness } \\
\text { Ground }\end{array}$ & Iconic ground & $\begin{array}{l}\text { Indexicality = } \\
\text { indexical ground }\end{array}$ & $\begin{array}{l}\text { Symbolicity = sym- } \\
\text { bolic ground }\end{array}$ \\
\hline $\begin{array}{l}\text { Thirdness } \\
\text { Sign }\end{array}$ & Iconic sign (icon) & $\begin{array}{l}\text { Indexical sign } \\
\text { (index) }\end{array}$ & symbolic sign (symbol) \\
\hline
\end{tabular}

Fig. 2. The relationship between principles, grounds, and signs, from the point of view of Peirce, as revised in the text.

41 For the discussion of indexicality here and in the next section, see more details in Sonesson (1989a; 1989b; 1993; 1994; 1995a; 1995b; 1996; 1998a; 1999; 2000a; 2001a; 2001c; 2003; in press a, b, c).

42 I have always taken Peirce to be committed to the view that, just as indexicality is co-extensive with the indexical ground, using the present terminology, so symbolicity is co-extensive with the symbolic ground as well as with the symbolic sign function. For my part, I rather tend to think that symbolicity also must be able to exist independently of the sign function, if it simply means something like "law-like relations". If Peirce thinks otherwise, this is no doubt because his sign concept is much broader than mine (for which see the third part of this essay). As he later recognised, it is better termed "mediation". Fig. 2 takes this difference into account, using a different background for the ground based on habituation and/or rules. 
If iconicity is Firstness, but the ground is a relation, which is Secondness, then the only solution, it seems to me, is to admit that, contrary to indexicality, iconicity is not in itself a ground: it is only something which may be used to construct a ground. Perhaps, to use some of Peirce's own examples, the blackness of a blackbird, or the fact of Franklin being American, can be considered iconicities; when we compare two black things or Franklin and Rumford from the point of view of their being Americans, we establish an iconic ground; but only when one of the black things is taken to stand for the other, or when Rumford is made to represent Franklin, do they become iconic signs (or hypoicons). Just as indexicality is conceivable, but is not a sign, until it enters the sign relation, iconicity has some kind of being, but does not form a ground until a comparison takes place. In this sense, if indexicality is a potential sign, iconicity is only a potential ground.

Stimulus generalisation and category membership may thus very well be examples of iconic grounds. They are certainly not iconicities, nor iconic signs. And they do not exhaust the domain of iconic grounds. $^{43}$

As is well-known (though Deacon does not attend to it), Peirce always cross-classifies Firstness, Secondness, and Thirdness in the sense of iconicity, indexicality and symbolicity, with the manifestation of these same general categories as Sinsign, Qualisign, and Legisign, as well as their manifestation as Rheme, Dicent, and Argument. In this way, Peirce manages to make more subtle distinctions, but none of them concern the issues that involve us here. Curiously, as Fig. 2 suggests, the distinctions that $d o$ interest us may also be expressed as a crossclassification of Firstness, Secondness, and Thirdness with itself, no doubt because Peirce's first trichotomy is really two different ones. However, this difference is hinted at in the work of Peirce, I believe, in oblique ways, with terms such as "genuine" or "pure" as opposed to "degenerate" instances of the three principles. If so, the present reconstruction will at least contribute to make our ideas clear.

43 After discussing indexicality, I will return to iconicity in section 1.5, where I will suggest that Deacon may not be so far from Peirce in his interpretation of iconicity after all. 


\subsection{The Chinese Room mystery:}

From the indexical ground to the indexical sign

On the face of it, Deacon's (1997: 77ff) notion of indexicality is less curious than the one he has about iconicity, but it is also very limited. He identifies indexicality with the conditioned reflex. It is a "repeated correlation" between two icons (in the idiosyncratic sense of categories): the smell of smoke repeated over and over again together with flames (index) presupposes the repetition of the phenomenon categorised as smoke as well as the phenomena categorised as flames (icons). This is Deacon's way of absorbing Peirce's contention that all indices contain icons. ${ }^{44}$ Expressed in more ordinary terms, the conditioned reflex depends on a double stimulus generalisation. The advantage of describing perception and learning in terms of iconicity and indexicality, respectively, is, in Deacon's view, to present them as processes of inference and prediction. This is indeed a very Peircean way of looking at our experience of the ordinary world. Indexicality is very intimately connected with abduction, the process by means of which we conclude from one single instance to another.

Numerous definitions of the index, which seem difficult to reconcile, are to be found in Peirce's work; and yet other interpretations are suggested by the examples given by Peirce himself, and even more so, if we also attend to those proposed by latter-day semioticians. According to the paraphrase formulated above, which seems sufficiently broad to account for most of the examples and a fair amount of the definitions, an index, is a sign in which the "thing" which serves as the expression is, in one or other way, connected with another "thing", which serves as its content. Although the two objects partaking of this relation of indexicality become a sign only by participating in a sign relation, the index relation must exist independently of the former. ${ }^{45}$

In the second place, since there are many conceivable types of connection between two things and, in particular, many ways in which they

\footnotetext{
44 Cf. note 36.

45 Normally, this would imply that the indexical relationship precedes the indexical sign function in real time, but there are exceptions to this: some signs create the very contiguity, which make them indexical (for instance arrows and pointing index fingers). In this case, it cannot be true that indexicality is completely independent of the sign function, as Peirce claims. (Cf. discussion about performative indices below and in Sonesson 1989a, I.2.5.)
} 
may be entered into, it is convenient to distinguish various kinds of indices (indexical signs) and indexicalities. This is not the place to enter into any details on the subject of indexicality, but a few varieties must be noted in the following (cf. also Sonesson 1989a, I.2.5; 1989b; 1992a; 1995b; 1999; 2001a). All indexical relations may involve either contiguity or factorality, that is, the relationship obtaining between the parts and the corresponding whole. Those indexicalities which are not as yet signs, being based on items which are not situated on different levels of directness or thematisation, or which are not clearly differentiated, may be described as contexts (or "pairings", in Husserl's sense). Any experience of two elements being related by proximity, conceived as a primordial perceptual fact, can be considered an actual perceptual context involving contiguity. An actual perceptual context involving factorality is any experience of something as being a part of a whole, or as being a whole having parts.

When only one of the items is directly given, and the other precedes it in time, or follows it, we may speak of an abductive context (protention and retention, respectively). The term abduction is employed here in Peirce's sense, to signify a general rule or regularity that is taken for granted and which links one singular fact to another. All experience taking place in time is of this kind, for instance our expectancy, when seeing the wood-cutter with the axe raised over his head, that in the following moment, he is going to strike the piece of wood (contiguity protention), and in the moment just preceding, he lifted the axe to its present position (contiguity retention). A case in point would also be the linguistic syntagm before it is completed, the foaming beer and feelings of refreshment, etc. Abductive contexts involving factorality would be, using in part some Peircean examples, the gait of the sailor, the symptom as part of the disease, part and whole in a picture, a partly destroyed Minoan fresco, a jig-saw puzzle, a piece of torn paper (the last three examples combine factorality and contiguity). ${ }^{46}$

When an indexicality has been stabilised, and objectified, into a real sign, it may become an abductive index, which can involve contiguity, as in the case of footprints, fingerprints, the cross as a sign of the cruci-

\footnotetext{
46 Although Deacon (1997: 399) at one point seems to deny the capacity of indices for representing future events (or is it only prescription?), he later (Deacon 1997: 465f) actually appears to identify such anticipation with indexicality, as when the animal expects some particular behaviour on the part of another animal, as distinct from deducing them from a "theory of mind".
} 
fied, the weather-cock (contiguity to the direction of the wind); or factorality, when an anchor is used to stand for navigation, the clock to designate the watch-maker's (as part of the sum total of clocks), or a painting to indicate the painter's workshop. Some of Peirce's examples, and many of those suggested later, are however of another kind, for, instead of presupposing a regularity known to obtain between the "thing" which serves as expression of the sign, and another "thing" which is taken to be its content, they transform something which is contiguous, or in a relation of factorality, to the expression, into the content of the latter. These signs may therefore be termed performative indices. With contiguity, they give rise to such phenomena as the pronoun "you", the finger pointing to an object, the weathercock (as marking the here-and-now of the wind), the clock of the watch-maker's (as marking the location of the shop); and with factorality, they may produce the pronouns "I", "here", "now", the finger pointing out a direction, etc. ${ }^{47}$

If we use the term indicator to describe signs which are employed to single out an object or a portion of space for our particular attention, all indices in Peirce's sense are certainly not indicators, and those which are cannot sufficiently be characterised by being so classified (cf. Sonesson 1989b: 50ff, 60f; 1995b; Goudge 1965: 65ff). ${ }^{48}$ Not all parts have as their primary function to point to the whole of which they are a part. On the other hand, real indicators, such as fingers and arrows, are equally contiguous to a number of objects which they do not indicate, for instance to the things which are at the opposite side of the arrowhead, in the direction to which it does not point (Sonesson 1989a: 47; 1995b). Therefore, something beyond mere indexicality is required, in the case of the arrow, for instance, the forward thrust of the arrow-head as imagined in water, or the sentiment of its slipping from our hands, as Thom (1973) has suggested.

To term certain signs "indicators" is, obviously, to make a categorisation of signs on the basis of their functions, as seen in relationship to

47 It is also possible to identify secondary indexical signs, including rhetorical figures known as synecdoches and metonymies. Cf. Sonesson 1989a, I.2.5 and 1999.

48 As pointed out in Sonesson (1995b), there is even a vague sense of "indicator" in which the latter does not have to be an index. As Deacon (1997: 362) observes, pointing is more or less the only universal gesture remaining in human beings, so perhaps it is the ancestor of indicators as well as indices - nota bene of indices, not of indexicality, because it is clearly a sign - and this applies to both "imperative" and "declarative pointing" in the sense of Bates (cf. Brinck 2004). 
the over-all scenes in which signs are produced. We should not expect this categorisation to coincide with the one stemming from Peirce's classification, which depends on the nature of the relationship between the expression and the referent or content of the sign. Of course, from this point of view, the term "index" is a misnomer, for although the finger so termed may function as an index, its specific function goes beyond that.

If indexical signs are as complex as this, it is obvious that they cannot be identified with conditioned reflexes, as Deacon suggests. But even the indexical ground goes well beyond the conditioned reflex. In fact, there is no necessity for the perceptual context to be repeated over and over again for us to interpret it indexically. One instance of a perceived contiguity or factorality may be sufficient to establish the corresponding indexical relation. And a long series of cases in which the expected contiguity or factorality does not obtain, does not necessarily lead to "extinction", contrary to Deacon's (1997: 82) claim. In fact our anticipation of rain when seeing dark clouds, or, to pick Deacon's own example, of fire when we perceive smoke, is so entrenched a semantical relation that it will not be abolished simply because it cannot always be realised in the world of our experience.

On the other hand, not only is the conditioned reflex an instance of the indexical ground, but so is the unconditioned reflex, whether it is innate or not. In fact, the unconditioned reflex is a pattern of behaviour, which is released, in the temporal and/or spatial contiguity of a particular feature of the experimental world (that is, the Umwelt). Thus, an indexical ground is formed not only between the sound sequence "food", and the edible substances that a rat may be conditioned to associate with it in the Skinner box, but also between these same substances, and the smell, colour, or other properties which the animal would use in real world circumstances as an identifying clue of the food. It could even be said that, while the unconditioned reflex depend on an abductive context (known regularity), the conditioned reflex is the result of a performative

\footnotetext{
49 As Stjernfelt (2001) points out, the conditioned reflex is already symbolic in Peirce's sense, no doubt because it supposes a regularity. But this only makes sense if Peirce is taken to be talking about mediation, not signs, according to the way these terms are interpreted here. See III below.
} 
context (posited regularity). ${ }^{50}$ However, from the point of view of the animal, this apparently amounts to the same.

However, it does not follow that "the association between the word and what it represents is not essentially distinguished from the kind of association that is made by an animal in a Skinner box" (Deacon 1997: 80). In particular, words like "there", "Aha!" and "George Washington", to quote Deacon's examples, and "shifters" in general, function very differently from conditioned reflexes. Indeed, just like the tracks interpreted by the hunter, which we opposed to the branch of the tree, when discussing the semiotic function, words which "derive reference by being uniquely linked to individual contexts", can only function as such if, at the same time as they are indexically connected to their context, they are clearly differentiated from it. If not, we would have no use for the real George Washington, once we knew his name. Indeed, Deacon's (1997: 82) reference to the fable of the Boy Who Cried Wolf is misleading: if we knew for other reasons that the boy was a confirmed liar, or that he was obsessed with wolves, we would not even from the beginning have expected a contiguity between his use of the word "wolf" and real-world wolves. However, if the conviction is sufficiently strong, no reality will ever be able to produce "extinction", as we have recently seen in the case of Iraqi weapons of mass destruction expected by the American leadership.

An excellent example of the difference between indices and indexicalities is the employment of warlike behaviour as a part of the Yanomamö peace ritual quoted by Deacon (1997: 403ff): if the participants had not made any difference between indexical signs and indexicalities (notably conditioned reflexes), the result would have been war, not peace. Perhaps this is also what Deacon wants to suggest, but he does so with a stereotypical, meaningless, formula, when he explains ritual from the fact of symbols having "a higher meaning" (Deacon 1997: 401f).

Of course, Deacon (1997: 83; cf. 301) knows that there is a difference: he suggests that "indexical power is distributed, so to speak, in the relationship between words". This is reminiscent of the binary reanalysis of the Peircean trichotomy, suggested by Jakobson (1979: 16) long ago, which, much to the displeasure of orthodox Peirceans, combines contiguity and similarity with actual and imputed connection. Ac-

50 In the case of an innate releasing mechanism, there is no prior experience of contiguity, but only a contiguity in the situation of release, so the term abductive context seems inappropriate. 
cording to this analysis, icons rely on actual similarity, indices on actual contiguity, and symbols on imputed contiguity. There remains a fourth category, based on imputed similarity, which in Jakobson's view, corresponds to the poetic function. In other contexts, I have pointed out several problematic features of this analysis (cf. Sonesson 1989a: 213f). Here, I will only note one of these: it is not clear where the imputed contiguity of symbols is to be located. If Jakobson wanted to refer to the contiguity of expression and content in the mind (which seems the only reasonable interpretation), then of course the same contiguity must also obtain for icons and indices. Contrary to Jakobson, Deacon would apparently accept such a consequence. It also appears more reasonable within the framework of Deacon's theory: the contiguity that he talks about is a contiguity of learning the signs. In our terms, this means that icons, indices and symbols, as opposed to the corresponding grounds, must be learnt in relation to other signs, not in relation to the nonsemiotic world. At least, this is how Deacon would have seen it, had he used our terminology. This will be clarified when we turn to the systemic nature of symbolic signification.

Before going on to discuss system character, however, I would like to point to a passage in which Deacon's vague and/or ambiguous concept of indexicality breaks down. It is in his discussion of the Williams syndrome, which he interprets as an incapacity to use index relations, coupled with a hypertrophy of symbolicity, resulting from a reduction of the posterior cerebral cortex and an exaggeration of the cerebellar size (cf. Deacon 1997: 268ff). Victims of this syndrome are verbally highly fluent, and adept at storytelling and the recital of verbal information, but have major cognitive deficits. It is, according to Deacon, as if they had ready access to lexical entries, that is, to the relationships between signs, as found in a thesaurus, but lacked all contact with reality, that is, the objects in the real world, to which the words refer. Thus, they get lost in symbolicity.

Here, Deacon really seems to identify indexicality with the link between the sign and the object in the real world, whereas symbolicity apparently characterises the internal structure of language, where words only point to other signs (an authentically Saussurean vision, as we shall see). This is, as we have already seen, a very reductionist view of indexicality, but it also seems to be in contradiction with what Deacon has said about the same notion earlier, on several levels. First, as an expression having reference (an indicator, notably), an index is certainly a 
sign, in which expression and content are differentiated (as in the verbal examples discussed above). It cannot be identified with "conditioned reflexes". ${ }^{51}$ Therefore, the patient may well have lost something more than mere indexicality. In the second place, if indexicality as such is unavailable, it seems that this must give rise to deficiencies on even more elementary levels. Third, it should produce problems also for the symbolic capacity, since the latter is described as a transposition of indexicality to the relations between signs, rather than between sign and reality (cf. Deacon 1997: 301). It is true that Deacon (1997: 302) talks about a "symbolic recoding", but the latter appears to consist precisely in the displacement of indexicality into the internal domain of language.

This brings us, in conclusion, to Deacon's (1997: 444ff) interpretation of Searle's exemplum of the Chinese Room: the man inside the room who, when he is given a message with a number of Chinese characters, responds by handing back another set of Chinese characters, which he takes out of a book where they are arranged as pairs, thus giving the false impression of understanding Chinese. According to Deacon, this highlights the difference between indexical and symbolic interpretation. The Chinese Room may certainly remind us of the Skinner box. Both, no doubt, are instances of the Black Box: we have no information of what is going on inside. That is, the exemplum supposes us not to have any information about what is going on in the room, but of course Searle has given it all away. As such, the Chinese Room does not only obliterate the difference between "symbols" and "indices", but equally that between the latter and mere indexicalities. If the man is really following Searle's instructions, then he is manipulating indexical signs: he is exchanging one token for another, because they are contiguous in the manual, as stated in the rules. But just as would a real Chinese, the Searlean man is producing the same facts on the ground as could a simple computer and perhaps some variety of the Skinnerean rat. From the outside of the Chinese room, we would not only be unable to tell the symbol from and index, but also to distinguish an index from a mere indexicality.

So far, I have tried to show that the nature of the link between two objects that may serve as the expression and content, respectively, of a sign, must be distinguished from the existence of a semiotic function relating these objects. Iconicity, indexicality, and symbolicity only de-

51 Nor does this seem to me to be a plausible interpretation of the purported indexicality of function words and the like (cf. Deacon 1997: 299). 
scribe that which connects the two objects; it does not tell us whether the result is a sign or not. ${ }^{52}$ The advantage of this analysis is not only theoretical clarity. It also allows us to formulate a series of questions, which could not have been conceived previously. It allows us to separate the study of the phylogenetic and ontogenetic emergence of iconicity, indexicality and symbolicity from that of the corresponding signs. However, we will now go on to suggest that the emergence of symbolic signs cannot itself be confounded with that of symbol systems.

\subsection{From "tone" to "type". A note on iconicity as generality and configuration}

It may seem that iconicity as such is not really needed in semiotic theory. If so, this could be the reason why Peirce points out that it is more or less impossible to grasp. But it is certainly indirectly needed. Even if iconicity only gains any real existence as an iconic ground, and thus as a relation, the ways in which iconicity and indexicality inhere in relations are different (cf. Fig. 2). Whereas both iconic and indexical grounds require a relation to function, the indexical ground is "about" this relation (its contiguity, its factorality, etc.), but the iconic ground is "about" the object at the other end of the relation. This is no doubt what Peirce wants to say when he claims that the items forming the icon are independent of each other, not only of the sign relation, as is the case of the index. If you think of the portrait painter trying to create the closest possible likeness to his model a literal interpretation of independence immediately becomes absurd - for, in this sense, the portrait can never be independent of its model (cf. Sonesson 2000a).

However, it is possible that "pure iconicity" has a more direct part to play, if not in Peirce's conception, then at least in Deacon's theory. Another of the manifestations of the Peircean trichotomy is the distinction between "qualisign", "signsign", and "legisign", sometimes also described with the terms "tone", "token", and "type". The opposition between token and type is straightforward (e.g. the letter " $\mathrm{t}$ " which as a

\footnotetext{
52 Of course, Peirce would have said that symbolicity does predict the sign character. I find this problematic, because if symbolicity describes the "general law" which is motivated by neither similarity nor contiguity, then it clearly exists independently of the sign function. There are many rules that are not sign functions. This is true, for instance, of etiquette and the rules of chess.
} 
type only manifests itself once in the sentence "The opposition between token and type is straightforward", although there are 7 corresponding tokens in the sentence), but it is more difficult to make sense of the notion of "tone". ${ }^{53}$ Contrary to the token, which is an individual instance, the tone seems to share some kind of generality with the type. But it is a kind of immediate impression of generality, not the organised, systematic kind found in the type. It is blackness, but not the category of blackness. It is certainly not recognition. It may be "black again", without "again" being part of the thought.

At least Deacon seems to be on to something like this, although this is really only borne out by his admission, in the section of suggested readings, that he has been influenced by "the classic text on Symbol Formation by Heinz Werner and Bernard Kaplan (1963)" (cf. Deacon 1997: 486). Now this is a text of Gestalt psychology, or, more properly speaking, Ganzheitspsychologie, but it is not, as far as I understand, much indebted to the well-known Berlin school (with such names as Köhler, Wertheimer, Koffka, Arnheim, etc.), but rather to the Leipzig school, represented, notably, by Krueger, Sander and Volkelt (cf. Sonesson 1989a, I.3.4.). This latter school insisted on the fact that there are wholes present in our experience which are not properly speaking Gestalten, that is, not typical configurations standing out from a background which are internally articulated (i.e. which have parts which may in due course be separated). Such non-configurational holistic properties are externally and internally diffuse (i.e. neither their parts nor their limits to other wholes is easy to distinguish), but they may yet be transposed from one context to another. Some properties of this kind are "closure" and "angularity". Another case in point is the child being unable to count who still has the experience of something being "a lot" or "a little". In none of these cases does the experience of sameness require the perception of category identity.

Elsewhere, I have suggested a double distinction between the meanings of meaning (cf. Sonesson 1989a, I.3.4 and I.4.2.): on the one hand, structure is opposed to configuration (including non-configurational wholes), and on the other hand, there is a distinction between categories and signs. While structural wholes result from the mutual

53 It is of course no accident that Peirce talks about "qualisigns", which is a term remiscent of the contemporary discussion of "qualia" (e.g. in Edelman, Tonini 2000). No doubt the philosophical antecedents are the same. However, Peirce is nowhere really preoccupied about how it feels to be conscious. 
relations between their components, including negative ones, a holistic whole is primarily a delimitation created in the field of perception, a setting up of borders, from which an inner differentiation may later ensue. Structures give rise to categories. But to reach the sign, we need the interrelation of two categories on different levels.

Human language is clearly both categorical and structural. That is also what Deacon thinks. But without pausing to consider, he attributes these properties to symbols in general.

\subsection{The house that Saussure built.}

From symbols to symbol systems

There is a double irony to Deacon's (1997: 69ff) plea for Peircean semiotics, as opposed to Saussurean "semiology". Not only does he impute to Saussure the very conception of language the Swiss linguist was out to criticise, but he ascribes to Peirce a conception of the symbol which, in a strict sense, is found nowhere is his work and which, in a loose sense, would really apply to all signs. Contrary to Deacon's selfunderstanding, his semiotics is really Saussurean at heart.

As anybody who has ever read a single paragraph of Saussure knows, his bete noire was - in the very terms that Deacons turns against him — the theory that words could be seen "as labels for objects, or mental images, or concepts" (ibid.). Saussure uses the same term ("etiquette") as Deacon to criticise this theory. He would heartily agree with Deacon that word meaning cannot "be modelled by an element-by-element mapping between two 'planes' of objects." Yet this is exactly the reproach that Deacon addresses to Saussure. In fact, Saussure (or the students who put together his Cours posthumously) may be responsible for the simple drawing of a circle divided into two halves, the signifier and the signified, but he also observed that such a conception was a gross oversimplification, because what really creates meaning in language is what he called "values", that is, the relations between signs, within an edifice where no terms are positive, and everything depends on everything else. Indeed, Deacon (1997: 70) sounds properly Saussurean when he says that "the correspondence between words and objects is a secondary relationship, subordinate to a web of associative 
relationships of a quite different sort, which even allows us reference to impossible things". 54

In contrast, Peirce claimed no such thing. When Deacon (1997: 96ff) says that symbols do not form "one-to-one associations" but "many-toone-associations" and "one-to-many-associations", Saussure would certainly agree. This is the very meaning of "structuralism", the linguistic tradition that Saussure is supposed to have initiated. Peirce, however, never discusses this issue. It is true that Peirce maintains that the three parts of the sign may themselves be made up of signs, that is, that the representamen, the object, and the interpretant can be dissolved into new signs, which themselves are made up of signs, and so on indefinitely. But nowhere does he tell us that such chains of signs are not linked by "one-to-one-associations". More crucially, he does not maintain that this model applies only to symbols, let alone linguistic signs. As far as can be gathered from the Peircean canon, the model applies equally well to icons and indices. ${ }^{55}$ Indeed, it is the Saussurean tradition, rather than the Peircean one, which has permitted Eco to oppose the thesaurus model of meaning to the dictionary model. But even in Eco's version, the model applies to all kinds of signs.

In the light of this close correspondence between Saussure's and Deacon's conception of language, it is not surprising that when defining a concept of language which goes beyond the linguistic system, they independently come up with the same examples, such as games, norms of etiquette, and ceremonies. In these cases, the system character of the signs seems to be fundamental to their meaning. But it is not true that this system character translates to all signs, nor to all symbols in the Peircean sense. Indeed, this has always been a problem for Saussurean "semiology", as practised by such French structuralists as Barthes.

The description of system character of language is later rephrased by Deacon (1997: 83ff) as "possibilities of combination". Commenting on the Rumbaugh experiments with chimpanzees, Deacon points to the difficulty of teaching somebody the impossibility of certain combinations. Language has a great number of combinatorial possibilities, but how is a poor ape to learn that "banana juice give" is not one of them? It is impossible to train what is not to be done. Therefore, in order to be

54 The latter is a point also made by Bouissac (2000) and Stjernfelt (2000).

55 Perhaps there is some justification for Deacon's view, for after all there is a famous quotation from Peirce, according to which "symbols grow". But this conception is nowhere elaborated. 
able to use a system, one must at some point recode indexical relations as symbolic ones. There is what Deacon $(1997: 92,95)$ calls "a symbolic threshold", where the individual gains an insight permitting the reorganisation of the whole system.

Deacon's combinatorial possibilities are reminiscent of the two aspects of the language system, described by Saussure, and later termed the syntagm and the paradigm by Hjelmslev. The syntagm is the set of signs appearing after each other in a combination of signs. The paradigm is the set of signs that may be substituted for each other at the same place in the syntagm. It is possible to generalise these terms, so that the syntagm is any set of signs appearing together, regardless of temporal and spatial relationships, whereas the paradigm consists of all signs that can be substituted for each other. Thus, the syntagm is made up of conjunctions, and the paradigm of disjunctions. Such a model applies very well to language and to games such as chess, as well as to restaurant menus and clothing, as Barthes has shown. However, as I have demonstrated elsewhere (cf. Sonesson 1992a, b), pictures as such do not have any paradigms and syntagms, although depicted objects (such as clothing) may be organised in that way, as may pictorial styles (the variety of colours permitted, different kinds of perspectives in different parts of the painting, as in Russian icons, cf. Uspenskij 1976; etc.). There are, however, other kinds of visual signs, which are not properly speaking pictures, which could be said to contain paradigms and syntagms, or at least the former: naval flag codes, graphic signs for washing instructions (such as those current in Sweden), traffic signs, etc. On the other hand, while complete gesture systems such as ASL certainly have syntagms and paradigms (which is why contemporary linguists insist on calling them "languages"), that is hardly true about many other kinds of gestures, for instance, emblems such a the V-sign.

It might be supposed that all sign systems have syntagms and paradigms. ${ }^{56}$ We have seen that some kinds of semiotic resources, in which iconic relationships are dominant, such as pictures, do not have system character in this sense. However, it does not follow that, as Deacon (1997: 100) maintains, "there can be no symbolisation without systematic relationships". If symbolicity is to be defined, as in Peirce conception, by the lack of both iconic and indexical motivation, then this does

56 In fact, perhaps only paradigms are required. At least on the level of complete units, traffic signs do not allow for any (or only a few) combinations, although they certainly offer a series of choices (cf. Posner 1989 and Sonesson 1998b). 
not imply anything about the system character of the signs. It is of course conceivable that there is some kind of "universal" which says that all signs that are constituted by means of symbolic relations are also organised into systems. It may even seem reasonable to argue this point: if signs are not held together either by iconicity or by indexicality, they may need to form part of a system in order not to loose their meaning. Or the other way round: if they are held together by a system, they do not need iconicity or indexicality.

Nevertheless, it is easy to show that this is not the case: if I decide with a friend that each time I have a particular shirt on, I want him to drive me home after the seminar, then this is a clear instance of a Peircean symbol. And yet, if we have not decided that not having this particular shirt on means the opposite, then there will not even be a minimal system. A lot of real world symbols are like that. If my example seems contrived, then this is not the case with the white walking stick used by blind people in some countries. Somebody not using a white walking stick does not convey the message "I am not blind", so there is not even a minimal system. On the other hand, the absence of a flag on the admiral ship does signify that the admiral in not onboard (cf. Prieto 1966: 43ff). The latter thus constitutes a minimal system, but its very minimality puts it on a level rather far from what Deacon is thinking about.

It should be clear by now that Deacon does not, in fact, have any use at all for Peirce's terminology. The system character of language, around which everything turns in the end, is not anything that is relevant to Peirce. The real criteria that define iconicity, indexicality and symbolicity are not interesting to Deacon.

On the other hand, I think that it is interesting for us to bring together the topics taken up by Deacon and the issues considered by Peirce. If symbolicity and systematicity are independent variables, then there is a series of empirical questions that may be formulated about them. If all symbols do not form part of sign systems, then is it at least true that all sign systems are made up of symbols? Perhaps semiotic resources of the kind in which iconic and/or indexical grounds dominate do not form sign systems. Then there is the historical issue: do we perhaps need to learn symbols first in the context of sign systems, before we can use them independently, unlike what happens with icons and indices? These are all empirical questions, which should be possible to investigate. 
Perhaps a new meaning could be given to the idea often expressed by the Tartu school, which has maintained that verbal language is primary in relation to the "secondary modelling systems", if the latter domain, since it involves systems, is restricted to symbols. In that case, language learning would really be a "semiotic threshold", which is important not only as such, but also for the new possibilities it opens up.

\section{The case for relevance. Beyond the Peircean Umwelt}

The following section has multiple goals. In the first place, I want to consider the "semiotic turn" in a part of biology that is not associated with cognitive science: biosemiotics, as first introduced by Hoffmeyer and Emmeche. In the second place, I will take into account a second interpretation of Peirce, which figures prominently in biosemiotics (but not only there), and which contrasts with my own interpretation in using the term "sign" in a very broad way. I will show that this interpretation leads to quite another conception of meaning, different from the sign, which is best paraphrased by such terms as relevance, filtering, and organisation. However, I will not abandon Deacon: on the contrary, at the end of the section, we will return to him with a vengeance. For it will be suggested that such concepts of meaning as are neglected or conflated with the sign in Deacon's work, and which we have introduced as iconicity (as opposed to the icon) and indexicality (as opposed to the index) are foreshadowed in this broader notion of meaning.

\subsection{Reading Peirce hermeneutically: the process of interpretation}

In all the earlier discussion, my point of departure has been an interpretation of Peirce, which I have found necessary to develop in order to defend the possibility of there being iconic signs, against such critics as Bierman and Goodman, who oppose to it the so-called arguments of symmetry and regression. The former argument says that, since similarity is symmetrical, it cannot explain the sign relation, which is asymmetrical; and the latter says that since all things in the world are similar to others in some respects (notably in relation to general categories such as "animate being", etc.), everything in the world could be a sign of 
everything else. Basically, those arguments can be countered by arguing that, apart from being iconic, an iconic sign must also manifest the semiotic function.

I still believe that this conception must correspond to something that Peirce was sometimes thinking about. There is, as we have seen, ample justification for some parts of this interpretation in the Peircean canon. In any case, this interpretation is needed in order to defend the theory against some arguments that have been formulated against it. And yet I think there is another theory in Peirce's work, which is not incompatible with the former, but which is considerably more general. It is concerned with interpretation in a more generic sense. Perhaps this is what Peirce was thinking about when, at a later stage, he discovered that his notions were too narrow, and that, instead of referring to signs, he should be talking about mediation or "branching".

In a sense, this theory is about the situation of communication, but it is more akin to what we now would describe as a hermeneutical model than to the model known from the theory of information. In this sense, "a sign is whatever there may be whose intent is to mediate between an utterer of it and interpreter of it, both being repositories of thought, or quasi-minds, by conveying a meaning from the former to the latter" (MS 318). ${ }^{57}$ In some passages, the object is not described a that which the sign is about, that is, to which it refers, in the sense in which this term is used in linguistic philosophy: instead, it is that which incites somebody to produce a sign (which may or may not coincide with the referent). It is in this sense that the object is Secondness: it concerns the relation between the reality perceived and the expression produced. Similarly, the interpretant must be seen as the result of the receiver taking in the whole event of the utterer creating an expression starting out from some feature of his experience. Because it refers to the relation between the utterer and that which he reacts to, it is more than an elementary relation, it is Thirdness. Indeed, this idea is very well illustrated by the notion of "branching" which Peirce used to characterise his later concept of mediation (cf. Fig. 3).

57 Quoted in Jappy, Tony (2000). Iconicity, Hypoiconicity. In: Quiroz, João; Gudwin, Ricardo (eds.), The Digital Encyclopaedia of Charles S. Peirce. (http://www.digitalpeirce.fee.unicamp.br/jappy/hypjap.htm). 


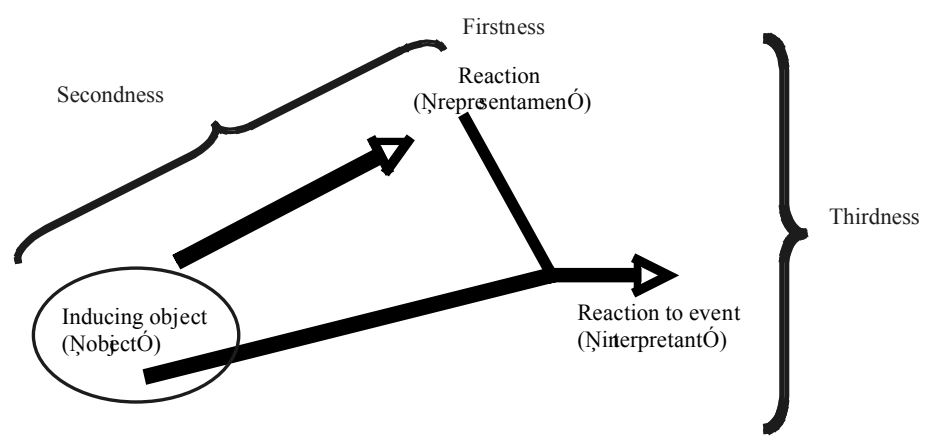

Fig. 3. A reconstruction of the hermeneutical interpretation of Peirce.

In this model, it is easier to understand that the parts of the signs are always also signs. On the other hand, it becomes much more complicated to make sense of the notions of iconicity, indexicality and symbolicity. In particular, it is not easy to see how they can be applied to the relation between the object and the representamen, if the latter is not, in some sense, the referent. Perhaps they should be understood in the sense of the principles, rather than the corresponding grounds, in the sense in which we discussed this in earlier chapters (cf. also Fig. 2.). Firstness, Secondness, and Thirdness, after all, are categories of human understanding, meant to function in the same way as the Kantian categories, that is, as schemes, or, to put it more simply, as filters determining our experience of the real world.

This model does nothing to justify Deacon's usage of the Peircean terminology, because it is too general to have anything to say about the issues that interest him. However, it is useful for the purpose of understanding the ground zero of meaning, semiosis, which may explain why it has been employed within biosemiotics to explicate von Uexküll's notion of meaning.

\subsection{The breed that Uexküll bred. Biosemiotics and the Kantian heritage}

Although the concept of sign is not clearly defined in Deacon's work, it certainly is a notion central to his concerns. There is, however, a domain 
of semiotics within which meaning is addressed in a much more general sense: biosemiotics. In the work of Hoffmeyer, for instance, even the cells are said to be involved in a process of interpretation. When exponents of biosemiotics such as Hoffmeyer (1997a; 1997b; 1997c; 1998) make use of Peircean concepts, they apparently do so in accordance with what we have called the second, hermeneutical reading. However, in order to understand what this is all about, it is more helpful to turn to the principal cultural hero of biosemiotics, Jakob von Uexküll.

Uexküll's $(1956$; 1973) notion of meaning centres on the environment, the Umwelt, which is differently defined for each organism (Fig. 4). As opposed to an objectively described ambient world, the Umwelt is characterised with respect to a given subject, in terms of the features which it perceives (Merkwelt) and the features which are impressed upon it (Wirkwelt), which together form a functional circle (Funktionskreis). According to a by now classical example, the tick hangs motionless on a branch of a bush until it perceives the smell of butyric acid emitted by the skin glands of a mammal (Merkzeichen), which sends a message to its legs to let go (Wirkzeichen), so that it drops onto the mammal's body. This starts a new cycle, because the tactile cue of hitting the mammal's hair incites the tick to move around in order to find its host's skin. Finally, a third circle is initiated when the heat of the mammal's skin triggers the boring response in order for the tick to drink the blood of its host. Together, these different circles consisting of perceptual and operational cue bearers make up the interdependent wholes of the subject, corresponding to the organism, and the Umwelt, which is the world as it is defined for the subject in question.

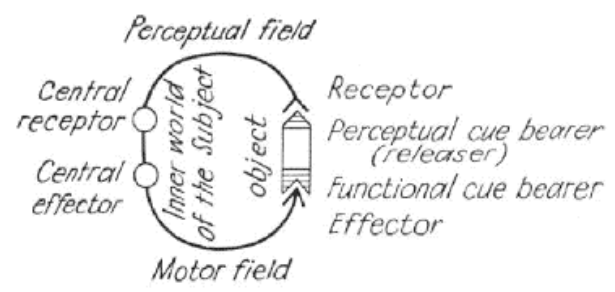

Fig. 4. The model of the Umwelt [functional cycle] according to Jakob von Uexküll (1973 [1928]: 158). 
Quoting Thure von Uexküll, Ziemke and Sharkey maintain that this model

contains all the elements which are part of a sign process, and whose interaction forms the unity of a semiosis: an organism is the subject (or interpreter), certain environmental signals play the role of signs (or interpretanda), and the organism's biological condition determines the behavioural disposition (or interpretant). The object (interpretatum), on the other hand, can be harder to identify using common sign-theoretical concepts, since for the organism, e.g. the tick, it does not necessarily exist as an abstract entity, e.g. 'a mammal', but might only have temporary existence as different semiotic objects and the bearer of varying meanings, e.g. three different ones in the tick's case. (Ziemke, Sharkey 2001: 709)

As is clear from the terminology, this conception of the "sign process" has little to do with Peirce, but owes a lot to Morris' behaviourist reinterpretation of the former. Even Peirce often uses the word "sign" in the sense of expression ("representamen"), but he certainly does not talk about the interpretant as a set of "behavioural dispositions"; however, it is perhaps not all too unreasonable to see the functional (or operational) cue bearers (Wirkzeichen) as being some variety of interpretants.

In any case, Ziemke and Sharkey's remark about the object is certainly judicious: that the object is, strictly speaking, nowhere to be found. ${ }^{58}$ In fact, they go on to quote an early text by von Uexküll, in which he says that "in the nervous system the stimulus itself does not really appear but its place is taken by an entirely different process" (my italics). Uexküll calls this a "sign", but it should be clear that is does not in any way fulfil the requirements of the semiotic function. Indeed, expression and content are not differentiated, already because they do not appear to the same consciousness. The butyric acid is there to the tick; the mammal is present only to us.

If we return to our earlier reconstruction of the Peircean sign process as a hermeneutic act (Fig. 3), we will discover that what is lacking is real Thirdness: the reaction to the primary reaction, that is, the reaction which does not respond to a simple fact (Firstness), but to something which is already a reaction, and thus a relation (Secondness). Without having to enter into the earlier discussion of differentiation, we see that, from a strictly Peircean point of view, there is no Thirdness for the tick:

58 As we shall see, the object is there, in a way, both as "immediate object" (the cues) and as "dynamical object" (the mammal). 
it does not respond to any relationship, since it is not aware (even in the most liberal sense of the term) of any second item (the mammal) to which the first item (the butyric acid) stands in a relation.

In fact, things are even more complicated. In a true sign relation, the mammal is not really the object, in the Peircean sense, for which the butyric acid is the representamen. Or, to be more precise, it is not the "dynamical object". At the very most, it is the "immediate object". It will be remembered that while the "immediate object" is that which directly induces the sign process, the "dynamical object" is something much more comprehensive, which includes all those things which may be known about the same object, although most of them are not present in the act of inducing. Indeed, the dynamical object is that which corresponds to the potentially infinite series of different interpretants resulting from the same original immediate object (cf. Fig. 5). It should be clear that, for the tick and similar beings, there can be no distinction between direct and dynamical object, because there is no room for any further development of the chain of interpretants. In this sense, Deacon's idiosyncratic reading of Peirce, according to which only signs such as those found in human language (his "symbols") give rise to chains of interpretants seem to have some justification - in reality, if not in Peircean theory.

We here enter a quite different, obviously Kantian domain: the mammal has become, to the tick, das Ding an sich, of which it can have no real knowledge. In a way, however, we are on familiar ground. It will be remembered that the categories of Firstness, Secondness, and Thirdness were designed by Peirce to occupy the position of the Kantian categories, that is the forms in which the world is given to us. More relevant, in the present context, however, is the presence of a concept of meaning within the Peircean sign concept that is similar to that of von Uexküll: the notion of ground. As I have pointed out elsewhere (and as Søren Brier 2001 has independently noted) the ground accounts for the difference, among other things, between the immediate and the dynamical objects. The butyric acid, the hairiness, and the warmth form the immediate objects of the tick, and we would expect the mammal as such to be the dynamical object. The difference, however, is that there is no way that the tick, unlike human beings, may learn more about the dynamical object than that which is given in the immediate one. Therefore, there is strictly speaking no difference between immediate and dynamical object to the tick. 


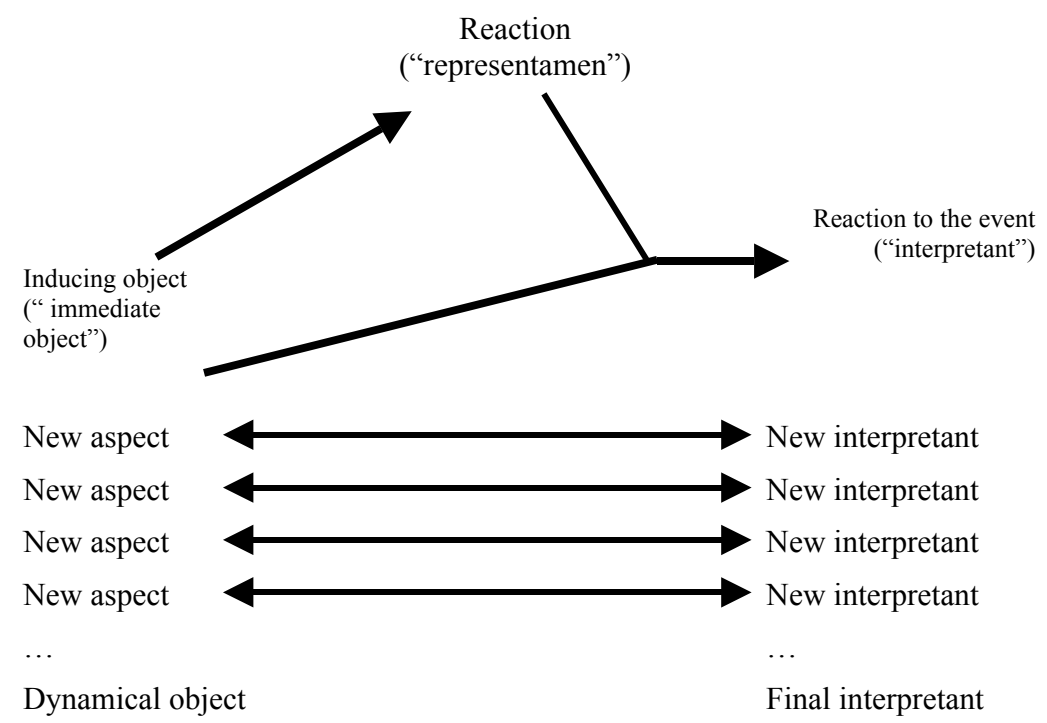

Fig. 5. A more complete reconstruction of the hermeneutical interpretation of Peirce's theory. New aspects are parts of the dynamical object (just as the immediate object) and are the support of new interpretations, which form a series.

Meaning here appears as a kind of "filter": it lets through certain aspects of the "real world" which, in is entirety, in unknowable, though less so for human beings than for ticks. Yet, as even Uexküll insists, it would be wrong to see the tick's world of experience as just a series of features extracted from reality. They are also organised into a whole. Indeed, this can best be expressed in terms of another Kantian philosopher, Karl Bühler, who talked about the principles of "abstractive relevance" and "apperceptive supplementation", where the first principle accounts for the neglect of such physical properties as are not endowed with meaning, while the second one explains the projection to the meaningful experience of properties not physically present in perception (Fig. 6). In fact, Bühler tried to explain the same linguistic phenomena as Saussure and Hjelmslev described in terms of "form" as opposed to "substance": the fact that certain properties of a physical sound may vary a lot without the units of meaning (the phoneme, the word, etc.) being changed; and that other properties which are not physically present may yet be 
perceived, because they are expected in the context. It can now be seen that Bühler's principles of abstractive relevance and apperceptive supplementation go much further than the sign. They have been found in the studies of the systems of cooking and clothing realised by LéviStrauss, Barthes, and others (cf. Sonesson 1989a).

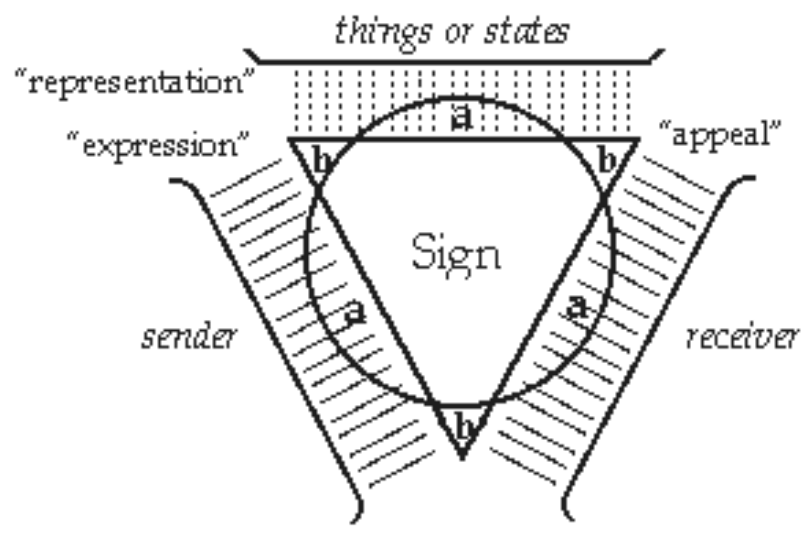

Fig. 6. Bühler's Organon model (with (a) 'abstractive relevance' and (b) 'abstractive supplementation'), from Bühler 1978 [1934]: 28.

The same general idea is found in the work of the cognitive psychologist Fredrick Bartlett (1932: 32, 44), who introduced the concept of scheme to account for our "effort after meaning". Bartlett used the notion of scheme in his studies of memory, in order to explain the successive modifications which a story stemming from an alien culture was subjected to, as the experimental subjects were asked to recount it from increasing temporal distances; but also in order to explain how one and the same drawing was transformed in later reproductions from memory, in different ways according as it had been labelled the first time as a pair of glasses or as a dumbbell. The scheme is to Bartlett "the setting which makes perceiving possible", and, more precisely, it is "an active organisation of past reactions, or of past experiences, which must always be supposed to be operating in any well-adapted organism's response", with the result that responses do not occur in isolation, but "as a unitary mass" (Bartlett 1932: 201). The last definition (in spite of introducing a 
socio-historical dimension) is reminiscent of Uexküll's notion of Umwelt.

This notion of schemes was used before Bartlett by Janet and Halbwachs, and it has been taken up later by Piaget, as well as by the phenomenologist Alfred Schütz (1932; 1967). It has of course also become a fundamental concept in cognitive psychology, linguistics, and artificial intelligence, but perhaps sometimes with a lower intentional depth. Elsewhere, I have summarised the results of these studies in the following way (Sonesson 1988): a scheme is an overarching structure endowed with meaning, which, with the aid of a relation of order, in the form of syntagms and/or paradigms, joins together a set of in other respects independent units of meaning. Among its further properties, two, in particular, are to be noted here: (a) schemes contain principles of relevance which extricate from each ineffable object such features as are of importance relative to a particular point of view (this is Piaget's assimilation, and the principle of abstractive relevancy, according to Bühler 1978 [1934]); (b) schemes also supply properties missing from the ineffable objects, or modify the objects so as to adapt them to the expectancies embodied in the schemes (this is another aspect of Piaget's notion of assimilation, and what Bühler terms apperceptive supplementation; also, it is involved in what Halbwachs $(1925 ; 1950)$ and Bartlett (1932) call reconstruction). ${ }^{59}$

Returning to modern-day biosemiotics, it can be easily shown that what these authors are involved in has nothing to do with meaning as sign function, but very much with meaning as relevance, organisation, configuration and/or filtering. In their early joint paper, Emmeche and Hoffmeyer (1991: 4), point out, in criticising the concept of information in information theory, that they are interested in "a difference that makes a difference to somebody". They go on to say that living beings "respond to selected differences in their surroundings" (their italics in both cases). This formulation clearly invokes relevance, and even some kind of filtering device. Later on in the paper, however, when the Peircean sign concept is introduced, the DNA-sequence of the gene is said to be the representamen, the protein its object, and the interpretant the cellular-biochemical network. It is difficult to detect any sign function

59 Some schemes incorporate (some of) the results of their own use on ineffable objects, and are themselves changed in the process, which is what Piaget calls accommodation, and perhaps what Lotman calls "internal recoding". Cf. Sonesson 1988, II.1.3.3. 
here, in the sense in which we have defined it. According to our authors, the contribution of Peircean semiotics is to show us that "the field of genetic structures, or a single gene, cannot be seen in isolation from the larger system interpreted" (Emmeche, Hoffmeyer 1991: 34). This certainly suggests meaning as a whole or a configuration. In a later paper, Emmeche (2002) sets out to show that in the living being function and meaning are the same. This can also be demonstrated, simply because Emmeche understands meaning in the sense of function: the relation of the part to the whole. But even in this article, there are traces of the filtering concept of meaning: we learn that "the whole operates as a constraint". Indeed,

Saying that cytochrome $c$ means something to the cell is the same as saying that it has a function. It is not just any molecule. We could well synthesise small proteins and artificially introduce them into the cell. They would be without importance or they would be dysfunctional or, with certain fortuitous strokes of luck, they would actually fulfil some function in the cell. (Emmeche 2002: 19)

This implies that the meaning of the enzyme "is structural" in the sense that "the cell's molecules form a system of dissimilarities (like the elements of language in Saussure" (Emmeche 2002: 20). This is of course true to the extent that there are relevancies in cells, in particular if these relevancies result from a system of oppositions, like those of Saussurean language. From this point of view, everything that is in the cells is also in language. But the opposite cannot be true. There is, of course, no semiotic function as we have defined it. Indeed, the semiotic function may be a function: but it is an external relationship between an expression and a content that are differentiated from each other.

It may be useful to distinguish two elements which often go together, both in Uexküll's notion of Umwelt and in the concept of scheme: organisation, which may derive from structure or configuration, and relevance, which may or may not be a result of organisation. It is clear that in language, as Saussure understands it, relevance is a result of organisation, and more exactly of structure. In Uexküll's notion of Umwelt, it rather seems to be a product of the configuration. ${ }^{60}$ Lacking the competence, I prefer not to pronounce myself in the case of genes.

60 My reason for saying so is that Uexküll insists that the three properties to which the tick reacts form a whole, or an experiential world, to the animal. This is the sense in which the Umwelt is a subjective concept (cf. Brier 2001). In denying 
It is useful also to distinguish relevance from filtering, although they do have something in common: the picking up of a limited set of features from the totality of the environment. However, relevance, strictly speaking, does not exclude anything: it merely places some portions of the environment in the background, ready to serve for other purposes. Thus, in the case of language, properties, which are not relevant for determining the meaning of the words and sentences, still may serve to inform us about the dialect, or even identify the person speaking (Hjelmslev's "connotational language"). Indeed, relevance lets the difference between immediate object and dynamical object subsist, in the vague sense which they retain in the hermeneutical interpretation of Peirce: that which is directly given, in contrast to that which is potentially given for further exploration. Thus, the principles of "abstractive relevance" and "apperceptive supplementation" still apply. In contrast, filtering simply strikes out that which is not let through the filtering device.

The difference between relevance and filtering no doubt has something to do with the capacity to be aware of the borders of one's Umwelt. It requires some kind of "metacognition", or, as cognitive scientists are want to say, "a theory of mind". To the tick, to paraphrase Wittgenstein, the limits of its language are the limits of its world, but not so to human beings. Or rather, the limits of our Umwelt are not the limits of our Lebenswelt.

\subsection{The Umwelt as Lebenswelt:}

from neural networks to Jakobson's law

Edmund Husserl introduced the term "Lifeworld" to describe the world taken for granted and shared by all human beings, as opposed to the constructed world of the physical sciences. ${ }^{61}$ Smith (2000; Smith, Varzi 1999) invokes ecological terminology to describe the Lifeworld as the niche in which human beings stake out their life. It is found on a

the robot an Umwelt, Emmeche (2001) also puts his emphasis on the experiential whole. Not being a biologist, I have some difficulty seeing why we have to suppose any connectedness between the features to which the tick reacts.

61 This is thus not the same concept of the "Lifeworld" referred to by Habermas, which is opposed to the "System world". From a Husserlean point of view, the latter would remain a part of the former. 
mesoscopic level, in between the microscopic and the macroscopic levels described in physics, but, in Smith's view, this level is real in the same sense as the latter two. If it is a niche, then it could perhaps also be described as an Umwelt.

Curiously, there is at least one other domain of semiotics, which shares with biosemiotics a concept of meaning that has nothing to do with signs. It is the semiotics of culture, as first defined by the Tartu school. In cultural semiotics, something has a meaning to the extent that it is part of our particular portion of the Lifeworld, what is, from our egocentric perspective, the Culture. Something coming to Culture from the outside, Non-culture, must first be translated into a text of Culture in order to acquire meaning. If it is declared a non-text, it looses its meaning (cf. Sonesson 1998a; 2000b; 2004). Thus, Culture takes the form of a filtering device. Indeed, if we follow the criteria offered by the Tartu school for the definition of culture, the latter even seems to have a lot to do with meaning as organisation, as scheme of interpretation, that is, as Umwelt. This may seem in many ways a limited model of the world, but it does account for some ways in which we tend to think about the relationship between different societies, in the contemporary world as well as throughout history.

According to the phenomenologist Aron Gurwitsch (1974), we may talk about different sociocultural lifeworlds, apart from the common structures of the Lifeworld, which we all share as human beings. Such a socio-cultural lifeworld would then correspond to a culture, in the sense of cultural semiotics. However, the phenomenologist Alfred Schütz (1967) suggested there really are "multiple provinces of meaning", such as dreaming, religious experience, the art world, the play world of the child, and that esoteric practise we know as science. The peculiarity of the Lifeworld, in this context, is that it offers access to the other worlds, and is accessible to all of them. In this sense, the human Lebenswelt is different from the Umwelt of other animals. Or at least it has the capacity to be different.

In Peircean terms, human beings may reach for the dynamical objects beyond the immediate ones. They may try to transform Nonculture into Culture. However, as Wittgenstein observed, even if we had a common language game, we would perhaps not have so much to talk about with a lion. The lion, presumably, does not try to go beyond his own Umwelt to grasp the properties of the objects that lie behind it. There is, so to speak, no dynamical object beyond the immediate one to 
him. And this is why there may not be much hope for us ever being able to discuss semiotics with a chimpanzee.

In spite of his background in biology, Deacon's concept of meaning is certainly not that of biosemiotics. To all appearance, relevance carries no interest to Deacon, and organisation only becomes interesting at a level of complexity that has nothing to do with the Umwelt of the tick. The biosemioticians and Deacon go fishing for very different concepts in the Peircean current of ideas. And yet I think our reconstruction of the biosemiotic concept of meaning will allow us to understand much better a crucial part of Deacon's theory.

It will be remembered that one formulation given by Deacon to what I have termed Deacon's problem is the difficulty of explaining the nonexistence of simple languages, that is, something which is similar to human language while being in some respects less complex. As a correlate, consider the fact that children, at an age when they are unable to learn many other things (because of their inability for sustained attention, their brief span of working memory, etc.), are better at learning language than they will ever be later. Together with the fact that the language data offered the child, that is, existing languages, are underdetermined with relation to the rules, this observation prompted Chomsky's postulation of a "universal grammar" functioning as a kind of innate "language acquisition device". However, Deacon (1997: 122ff) very plausibly suggests that these facts can be given another explanation. It is, as he puts it, the very immaturity of the child that allows it to discover language structure. Taking a clue from Elisa Newport, he suggests that "less is more": children's advantages consist in their not being able to take in all there is. Jeff Elman, quoted by Deacon (1997: 129ff), showed that while an unconstrained neutral network could not pick out correctly the structure of a language sample, because it got bogged down by low-level regularities, the network produce much more adequate results when starting out from a small sample of simple sentences which was gradually extended, or when "noise" was periodically introduced into the machinery. If this is what happens when children learn language, innate rules of universal grammar are not needed.

Deacon's own interpretation of these facts is reminiscent of our discussion in the last section. First, he claims that, in the neural network, "what was available for learning at early stages was 'filtered' [...], so that only some aspects of the input were available at any time" (Deacon 1997: 134). Here the very term of "filtering" appears. Then, proceeding 
to talk about children, he suggests that "the relevant large-scale logic of language 'pops out' of a background of other details too variable for them to follow, and paradoxically gives them a biased head start" ( $p$. 135). This passage more directly suggests the concept of relevance. Perhaps we should not disregard this difference in terminology. Relevance, as opposed to filtering, implies the availability of a dynamical object, beyond the immediate one. It roughly corresponds to what $\mathrm{Vy}-$ gotsky calls the "zone of proximal development".

If the Umwelt is an organised network of filters and/or relevancies, as I suggested in the last section, maturing in the child seems to consist in breaking out of one Umwelt and going on into another, broader one, until reaching the human Lifeworld. Between each Umwelt and the next, which encompasses it, there is always a zone of proximal development. In this sense, ontogenesis itself forces us to go through a series of "finite provinces of meaning", in the sense of Schütz. A temporal dimension is thus added. If it is still needed, it might also be said that, from the earliest stage to the later ones, with the introduction of structure, the child also passes from features in the form of Peircean "tones" (Deacon's icons) to "types".

Understood in this way, our Russian doll model of Umwelten does not lack precedents. One clear case seems to me to be Jakobson's (1942) conception of the development of phonological distinctions, which, according to his claims, follows a more or less fixed order in all the languages of the world. Jakobson's law really comprises three distinct theories: about the language learning of the child, the language loss of the aphasic, and the common traits of all languages. As I noted in another context (cf. Sonesson 1989a, I.3.4), none of these systems of precedence relations (except perhaps the last) necessarily coincides with the set of units that the normal adult perceives in his language, in particular if this is a system "où tout se tient", as the structuralist saying goes. In the heyday of universalism, Jakobson's theory was interpreted as involving a subset of language universals, together with the colour terms, and of course Chomsky's syntax (cf. Holenstein 1985). But just as Deacon says with reference to the precedence relations between colour terms according to the theory of Berlin and Kay, there is no need to interpret Jakobson's system as being in any sense innate. At least as applied to the child, the principles simply say that it starts out attending to only that which is common to a set of similar units in the language of 
the adult. The rest is "filtered" out, but remains at the margin, being incorporated in later versions of the child's Umwelt.

When I referred to Jakobson's law in an earlier publication, my main purpose was to find out to what extent a parallel development could be found in quite a different domain, that of visual shapes (cf. Sonesson 1989a, II.3.6. and note 9 to I.1.). For our present purpose, this is interesting to the extent that it would show that such principles, if they are at all innate, are not specific to linguistic development. There unfortunately are very few empirical investigations to base any such theories on. Therefore, the main basis of my discussion was Lotte Hoffmann's (1943) investigation into the way children, between 2.2 and 9.7 years of age, behave when they are urged to imitate some simple geometrical configurations using readymade material, like sticks, plates, and rings. ${ }^{62}$ The youngest children offer what Hoffmann (1943: 39ff) calls "Etwaslösungen", i.e. the solution through anything whatever. Interestingly, no matter which configuration is imitated, the objects used are predominantly the round ones and those that are filled rather than those having contours. Later the child will produce "Sowaslösungen" (Hoffmann 1943: 55ff), again using only one piece, not to imitate proper parts of the configuration, but to render properties, or attributes, of the configuration, such as being closed, angular, pointed, having holes, and so on. Even though all configurations have contours, and some are angular, the child will often choose objects to imitate them which are filled and rounded, and which furthermore share some other property with the object imitated. Unfortunately, Hoffmann's indications are insufficient to build an hierarchy as complete as that suggested by Jakobson, but at least we can sketch a provisional model, in which an initial "tone" of "anything at all" is represented by a filled circle, which later gives way to a distinction between the straight line and the filled circle, further branching out into the opposition between the filled and the contoured circle.

The general principle thus seems to hold true. Of course, this happens much later in child development, and it is most definitely a case of relevance rather than filtering: the child certainly perceives everything that is does not care to represent.

62 Explanations based on the child's limited manual dexterity could be ruled out because of the ready-made material used for the task. 


\section{Concluding remarks}

In this essay, I have tried to show that semiotic concepts in general, and the concept of sign in particular, are useful for discussing many of the issues relevant to cognitive science. More specifically, I have suggested that scholars who, like Deacon, take an interest in semiotical development, need to use a more complex terminology when talking about phenomena endowed with meaning. The semiotic function, it has been suggested, is quite separate from iconic, indexical, and symbolic grounds, and may or may not be combined with them. And system character may be found or not in symbolic signs. The advantage of this terminology is first and foremost to allow for the formulation of a series of questions which may be empirically investigated, bearing on the systematic as well as temporal interconnectedness of symbolicity, the sign function, and systematicity. Specifically, by defining the sign independently of the particular type of motivation connecting expression and content (iconicity, indexicality, symbolicity) as well as of the system character joining it to other signs, a number of hypotheses concerning semiotic development (in phylogeny and ontogeny) can be formulated and tested. Even if iconicity and indexicality as such precede the emergence of the sign, it is conceivable that true signs first appear as symbols. And even if system character and arbitrariness come together in verbal language, it is possible that they are quite independent, or that one of them serves as the cause of the other. Deacon's theory embodies a specific hypothesis within this framework: that sign function, symbolicity and system character necessarily go together. But he presents no theoretical or empirical arguments for this hypothesis. He takes the relationship for granted.

In the second part of the essay, we looked at a much broader concept of meaning than that of the sign, used in biosemiotics as well as in cultural semiotics, and we showed that it was not only a prerequisite for the sign, but that it also had a use of its own. Even if meaning, in this general sense (as organisation and most of all as relevance) is implied in the sign concept, we cannot know whether it is contemporaneous with it, or develops even earlier. In this case, however, the second hypothesis sounds more reasonable. Indeed, we used Deacon's description of how language learning is possible to illustrate the workings of this broader concept of meaning, and we added a parallel from the development of visual shapes. In the end we therefore had to conclude, not only that by 
making our terminology clear, we can shed some new light on Deacon's theory; but Deacon's ideas have also helped in developing some fragments of the theory of semiotic development.

It has been suggested by Kalevi Kull (2005) that there is a primary semiotic threshold opposing physics (that which is not alive) to biology (living things, including internal biological processes, known since Sebeok as endosemiotics), and that there is a secondary semiotic threshold, which opposes the latter to that which is language-like (discussed in sociology and semiotics of culture). ${ }^{63}$ In view of the earlier discussion, it seems to me that further thresholds could be usefully introduced (Fig. 7). I would posit the first threshold, just as Kull does, between that which is not alive and that which is alive: non-semiotic vs. semiotic. I would, however, separate that which only becomes meaningful to the investigator, such as endosemiotic processes, from that which can only function as such when seen as semiotic, which would oppose that which is purely meta-semiotic to that which is semiotic sui generis. Within the latter domain, I think we should at least separate purely mediational semiosis from sign-based semiosis. This latter distinction is the one which is at stake in Deacon's book. It is, also, I think, the one with which we must be involved, if we really want to understand the difference between human beings and other species. ${ }^{64}$

63 Lecture given in the framework of the SGB-seminars [Språk, gester och bilder - "Language, Gestures and Pictures in the Perspective of Semiotic Development"] at Lund University, May 20, 2006.

${ }^{64}$ Acknowledgements. I would like to acknowledge the stimulating comments offered on an earlier version of this paper by the members of the project "Language, gesture, and pictures from the point of view of semiotic development". In particular, I have learnt a lot from Jordan Zlatev's extensive and thorough critique of several versions of the text. Moreover, the discussions of some papers by Hoffmeyer, Emmeche, Kull and Brier during some of my Semiotics Seminars in Lund have been very enlightening. A preliminary version was "published" on the net as Working Paper 3 of the SGB project. Since then I have received some observations by John Michel Krois. In addition, Paul Bouissac (2000) and Frederik Stjernfelt $(2000 ; 2001)$ have pointed out to me that they have published reviews of Deacon's book, which is a fundamental theme of the first part of this essay. Also, Sara Lenninger directed me to the review of Deacon written by Lumsden (2002). Although I was not aware of these texts when writing the earlier versions of this paper, we all agree that Deacon's understanding of Peirce is faulty. Stjernfelt and Bouissac note, as I do, that Deacon is closer to Saussure than he likes to think, and Lumsden claims, just like me, that the Peircean terminology serves to obscure Deacon's own central issues. However, the thrust of the present argument is entirely different. Finally, I would like to thank Ingrid Nilsson for her spon- 


\begin{tabular}{|c|c|c|c|}
\hline non-semiosis & not-alive & & physics \\
\hline \multicolumn{4}{|r|}{ first threshold } \\
\hline $\begin{array}{l}\text { (pure) meta- } \\
\text { semiosis }\end{array}$ & $\begin{array}{l}\text { alive but not given } \\
\text { to everyday percep- } \\
\text { tion }\end{array}$ & $\begin{array}{l}\text { so-called endo- } \\
\text { semiotic processes }\end{array}$ & biology \\
\hline \multicolumn{4}{|r|}{ second threshold } \\
\hline $\begin{array}{l}\text { mediational } \\
\text { semiosis }\end{array}$ & $\begin{array}{l}\text { that which only } \\
\text { functions as such } \\
\text { when seen as } \\
\text { meaningful }\end{array}$ & $\begin{array}{l}\text { perception, or- } \\
\text { ganisation, per- } \\
\text { ceptual categori- } \\
\text { zation, etc. }\end{array}$ & $\begin{array}{l}\text { biology as ethology, } \\
\text { ecology, etc.; psychol- } \\
\text { ogy of perception and } \\
\text { cognition }\end{array}$ \\
\hline \multicolumn{4}{|r|}{ third threshold } \\
\hline sign semiosis & $\begin{array}{l}\text { that which only } \\
\text { functions as such } \\
\text { when seen as } \\
\text { meaningful and } \\
\text { differentiated }\end{array}$ & $\begin{array}{l}\text { signs and sign } \\
\text { systems such as } \\
\text { language, pictures, } \\
\text { gesture }\end{array}$ & $\begin{array}{l}\text { psychology of cogni- } \\
\text { tion, cognitive science. } \\
\text { visual semiotics; sociol- } \\
\text { ogy, anthropology, } \\
\text { semiotics of culture }\end{array}$ \\
\hline
\end{tabular}

Fig. 7. The three thresholds of semiosis (cf. Kull 2005: 181, Table 1).

\section{References}

Bartlett, Fredrick C. 1932. Remembering: A Study in Experimental and Social Psychology. Cambridge: Cambridge University Press. [Reprint 1967.]

- 1958. Thinking: An Experimental and Social Study. London: Allen \& Unwin Ltd.

Bentele, Günter 1984. Zeichen und Entwicklung: Vorüberlegungen zu einer genetischen Semiotik. Tübingen: Narr.

Bierman, Arthur K. 1963. That there are no iconic signs. Philosophy and Phenomenological Research 23(2): 243-249.

Bouissac, Paul 2000. Steps toward evolutionary semiotics. Semiotica 132(3/4): $317-342$.

Brier, Søren 2001. Cybersemiotics and Umweltslehre: On the cybersemiotic integration of 'Umweltlehre', enthology, autopoiesis theory, second order cybernetics and Peircean bisosemiotics. Semiotica 134(1/4): 779-814.

Brinck, Ingar 2004. The pragmatics of imperative and declarative pointing. Cognitive Science Quarterly 3(4): 1-18.

taneous proofreading of an earlier version of the text, which has been very useful, even if I was not always convinced by her suggestions. 
Bruss, Elisabeth 1978. Peirce and Jakobson on the nature of the sign. In: Bailey, Richard W.; Matejka, Ladislav; Steiner, Peter (eds.), The sign - Semiotics around the world. Ann Arbor: Michigan Slavic Contributions, 81-98.

Bundgård, Peer; Egholm, Jesper; Skov, Martin (eds.) 2003. Kognitiv Semiotik. København: Haase \& Søns Forlag AS.

Bühler, Karl 1978 [1934]. Sprachtheorie. Frankfurt am Main: Ullstein. [Stuttgart: Fischer.]

Cabe, Patrick 1980. Picture perception in nonhuman subjects. In: Hagen, Margaret A. (ed.), The Perception of Pictures. Vol. 2: Dürer's Devices. New York: Academic Press, 305-343.

Callaghan, Tara; Rankin, Mary 2002. Emergence of graphic symbol functioning and the question of domain specificity. Child Development 73(2): 359-376.

Deacon, Terrence 1997. The Symbolic Species: The Co-evolution of Language and the Brain. New York: Norton.

Deely, John 1982. Introducing Semiotic: Its History and Doctrine. Bloomington: Indiana University Press.

- 1994. New Beginnings: Early Modern Philosophy and Postmodern Thought. Toronto: University of Toronto Press.

- 2001. Four Ages of Understanding. Toronto: University of Toronto Press.

Deloache, Judy 2000. Dual representation and young children's use of scale models. Child Development 71(2): 329-338.

- 2004. Becoming symbol-minded. Trends in Cognitive Sciences 8(2): 66-70.

Deloache, Judy; Burns, Nancy 1994. Early understanding of the representational function of pictures. Cognition 52: 83-110.

Deloache, Judy; Miller, Kevin; Rosengren, Karl 1997. The credible shrinking room. Psychological Science 8(4): 308-313.

Deregowski, Jan 1973. Illusion and culture. In: Gregory, Richard L.; Gombrich, Ernst H. (eds.), Illusion in Nature and Art. London Duckworth \& Co, 160191. [Third impression 1980.]

— 1976. On seeing a picture for the first time. Leonardo 9(1): 19-23.

Donald, Merlin 1991. Origins of the Modern Mind: Three Stages in the Evolution of Culture and Cognition. Cambridge: Harvard University Press.

Eco, Umberto 1998. Réflexions à propos du débat sur l'iconisme (1968-1998). Visio 3(1): 9-32.

- 1999. Kant and the Platypus. New York: Harcourt Brance \& Co.

Edelman, Gerald M.; Tonini, Giulio 2000. A Universe of Consciousness: How Matter Becomes Imagination. New York: Basic Books.

Ekman, Paul; Friesen, Wallace 1969. The repertoire of non-verbal behaviour: Categories, origins, usage, and coding. Semiotica 1: 49-98.

Emmeche, Claus 2001. Does a robot have an Umwelt? Semiotica 134(1/4): 653693.

- 2002. The chicken and the Orphean egg. On the function of meaning and the meaning of function. Sign Systems Studies 30(1): 15-32.

Emmeche, Claus; Hoffmeyer, Jesper 1991. From language to nature - the semiotic metaphor in biology. Semiotica 84(1/2): 1-42. 
Eysenck, Michael W.; Keane, Mark T. 1995. Cognitive Psychology: A Student's Handbook. 3rd ed. Hillsdale: Lawrence Erlabaum Ass.

Fagot, Joel (ed.) 2000. Picture Perception in Animals. Hove: Psychology Press.

Foley, Robert A. 1991. The silence of the past. Nature 353: 114-115.

Gardner, Howard; Wolf, Dennie 1983. Waves and streams of symbolization: Notes on the development of symbolic capacities in young children. In: Sloboda, John; Rogers, Deborah (eds.), The Acquisition of Symbolic Skills. New York: Plenum Press, 19-42.

Gibson, James 1966. The Senses Considered as Perceptual Systems. Boston: Houghton Mifflin.

- 1980. A prefatory essay on the perception of surfaces versus the perception of markings on a surface. In: Hagen, Margaret (ed.), The Perception of Pictures, Vol. 1: Alberti's Window. New York: Academic Press, xi-xvii.

- 1982. Reasons for Realism. Selected Essays of James J. Gibson. (Reed, Edward; Jones, Rebecca, eds.) Hillsdale: Lawrence Erlbaum Ass.

Goodman, Nelson 1968. Languages of Art: An Approach to a Theory of Symbols. London: Oxford University Press.

- 1970. Seven strictures on similarity. In: Foster, L.; Swanson, J. W. (eds.), Experience and Theory. Cambridge: University of Massachussets Press, 1929.

Goudge, Thomas A. 1965. Peirce's index. Transactions of the Charles S. Peirce Society 1: 152-170.

Greenlee, Douglas 1973. Peirce's Concept of Sign. The Hague: Mouton.

Greimas, Algirdas J.; Courtés, Joseph 1979. Sémiotique: Dictionnaire raisonné de la théorie du langage. Paris: Hachette.

Groupe $\mu$ (Dubois, J.; Edeline, F.; Klinkenberg, J. M.; Minguet, P.; et al.) 1992. Traité du signe visuel: Pour une rhétorique de l'image. Paris: Seuil.

- 1995. Iconicism. In: Sebeok, Thomas A.; Umiker-Sebeok, Jean (eds.), The Semiotic Web 1992/93: Advances in Visual Semiotics. Berlin: Mouton de Gruyter, 21-46.

Gurwitsch, Aron 1957. Théorie du champs de la conscience. Bruges: Desclée de Brouver.

- 1974. Phenomenology and the Theory of Science. Evanston: Northwestern University Press.

Halbwachs, Maurice 1925. Les cadres sociaux de la mémoire. Paris: PUF. [Second edition 1952.]

- 1950. La mémoire collective. Paris: PUF. [Second revised edition 1968.]

Hauser, Mark 1997. The Evolution of Communication. New York: MIT Press.

Hochberg, Julian 1972. The representation of things and people. In: Gombrich, Ernst H.; Hochberg, Julian; Black, Max (eds.), Art, Perception, and Reality. Baltimore: John Hopkins University Press, 47-94.

- 1978. Perception. Englewood Cliffs: Prentice-Hall. [Second, revised edition.]

Hochberg, Julian; Brooks, Virginia 1962. Picture perception as an unlearned ability. American Journal of Psychology 76: 624-628.

Hockett, Charles 1977. The View from Language. Athens: University of Georgia Press. 
Hoffman, Lotte 1943. Vom schöpferischen Primitivganzen zur Gestalt. München: Beck'sche Verlagsbuchhandlung. [New edition 1961.]

Hoffmeyer, Jesper 1997a. The swarming body. In: Rauch, Irmgard; Carr, Gerald F. (eds.), Semiotics Around the World: Synthesis in Diversity. Proceedings of the Fifth International Congress of the IASS, Berkeley, June 12-18, 1994. Berlin: Mouton de Gruyter, 937-940.

- 1997b. Biosemiotics: Towards a new synthesis in biology. European Journal for Semiotic Studies 9(2): 355-376.

- 1997c. The global semiosphere. In: Rauch, Irmgard; Carr, Gerald F. (eds.), Semiotics Around the World: Synthesis in Diversity. Proceedings of the Fifth International Congress of the IASS, Berkeley, June 12-18, 1994. Berlin: Mouton de Gruyter, 933-936.

- 1998. Semiotic emergence. Revue de la pensée d'aujourd'hui 25/27(6): 103117.

Holenstein, Elmar 1985. Sprachliche Universalien: Eine Untersuchung zur Natur des menschlichen Geistes. Bochum: Brockmeyer.

Husserl, Edmund 1939. Erfahrung und Urteil. Prag: Academia Verlagsbuchhandlung.

Itakura, Shoji 1994. Recognition of line-drawing representations by chimpanzees (Pan troglodytes). Journal of General Psychology 121: 189-197.

Jakobson, Roman 1942. Kindersprache, Aphasie und allgemeine Lautgesetze. Uppsala: Uppsala University.

- 1965a. À la recherche de l'essence du langage. Diogène 51: 22-38.

- 1965b. Poesie der Grammatik und Grammatik der Poesie. In: Gunzenhäuser, R.; Kreuzer, H. (eds.), Mathematik und Dichtung, München: Nymphenburger Verlagsbuchhandlung, 21-32.

- 1979. Coup d'œil sur le développment de la sémiotique. In: Chatman, Seymour; Eco, Umberto; Klinkenberg, Jean-Marie (eds.), A Semiotic Landscape/Panorama sémiotique. Actes du premier congrés de l'assoclatlon internationale de sémiotique, Milan, juin 1974. The Hague: Mouton, 3-18.

Johansen, Jørgen Dines 1993. Dialogic Semiosis. Bloomington: Indiana University Press.

Johnson, Mark 2005. The philosophical significance of image schemas. In: Hampe, Beate (ed.), From Perception to Meaning: Image Schemas in Cognitive Linguistics. Berlin: Mouton de Gruyter, 15-34.

Johnson-Laird, Philip N. 1988. The Computer and the Mind: An Introduction to Cognitive Science. Cambridge: Harvard University Press.

Kendon, Adam 2004. Gesture. Cambridge: Cambridge University Press.

Kita, Sotaro (ed.) 2003. Pointing: Where Language, Culture and Cognition Meet. Hillsdale: Lawrence Erlbaum.

Kolers, Paul 1977. Reading pictures and reading text. In: Perkins, David; Leondar, Barbara (eds.), The Arts and Cognition. Baltimore: Johns Hopkins University Press, 136-164.

Kuhlmeier, Valerie; Boysen, Sarah 2001. The effect of response contingencies on chimpanzee scale model task performance. Journal of Comparative Psychology 115(3): 300-306. 
Kuhlmeier, Valerie; Boysen, Sarah 2002. Chimpanzees' recognition of the spatial and object similarities between a scale model and its referent. Psychological Science 13(1): 60-63.

Kuhlmeier, Valerie; Boysen, Sarah; Mukobi, Kimberly 1999. Scale model comprehension by chimpanzees (Pan troglodytes). Journal of Comparative Psychology 113(4): 396-402.

Kull, Kalevi 2005. Semiosphere and dual ecology: Paradoxes of communication. Sign Systems Studies 33(1): 175-189.

Lakoff, George; Johnson, Mark 1999. Philosophy in the Flesh. New York: Basic Books.

Lindblom, Jessica; Ziemke, Tom 2003. Social situatedness of natural and artificial intelligence: Vygotsky and beyond. Adaptive Behvior 11(2): 79-96.

Locke, John 1965 [1706]. An Essay Concerning Human Understanding. Yolton, John W., ed. London: Dent.

Lombardo, Thomas 1987. The Reciprocity of Perceiver and Environment. Hillsdale: Lawrence Erlbaum.

Lumsden, David 2002. Crossing the symbolic threshold. Philosophical Psychology 15(2): 155-171.

Mertz, Elisabeth; Parmentier, Richard J. (eds.) 1985. Semiotic Mediation: Sociocultural and Psychological Perspectives. Orlando: Academic Press.

Osmond-Smith, David 1972. The iconic process in musical communication. Versus 3: 31-42.

Posner, Roland 1989. What is culture? Toward a semiotic explication of anthropological concepts. In: Koch, Walter A. (ed.), The Nature of Culture. Bochum: Brochmeyer, 240-295.

Peirce, Charles Sanders 1931-1958. Collected Papers I-VIII. Hartshorne, Charles; Weiss, Paul; Burks, Arthur (eds.). Cambridge: Harvard University Press.

Piaget, Jean 1945. La formation du symbole chez l'enfant. Neuchatel: Delachaux \& Niestlé. [Third edition 1967.]

- 1967. La psychologie de l'intelligence. Paris: Armand Colin.

- 1970. Epistémologie des sciences de l'homme. Paris: Gallimard.

Prieto, Luis 1966. Messages et signaux. Paris: PUF.

- 1975a. Pertinence et pratique: Essai de sémiologie. Paris: Minuit.

- 1975b. Essai de linguistique et sémiologie générale. Genève: Droz.

Reed, Edward S. 1988. James J. Gibson and the Psychology of Perception. New Haven: Yale University Press.

Rosch, Eleanor, 1975a. Cognitive representations of semantic categories. Journal of Experimental Psychology: General 104(3): 192-233.

- 1975b. Cognitive reference points. Cognitive Psychology 7(4): 532-547.

- 1975c. The nature of mental codes for color categories. Journal of Experimental Psychology: Human Perception and Performance 1(4): 303-322.

Rosch, Eleanor; Mervis, Carolyn B.; Gray, Wayne; Johnson, David; BoyesBraem, Penny 1976. Basic objects in natural categories. Cognitive psychology 8(3): $382-439$. 
Rosch, Eleanor; Simpson, Carol; Miller, R. Scott 1976. Structural bases of typicality effects. Journal of Experimental Psychology: Human Perception and Performance 2(4): 491-502.

Saussure, Ferdinand de 1968-1974. Cours de linguistique générale I-II. Edition critique par Rudolt Engler. Wiesbaden: Harrossowitz.

Savan, David 1976. An Introduction to C. S. Peirce's Semiotics. Toronto: Toronto Semiotic Circle.

Schütz, Alfred 1932. Der sinnhafte Aufbau der sozialen Welt. Vienna: Springer. [New edition 1974, Frankfurt am Main: Suhrkamp.]

- 1967. Collected Papers I: The Problem of Social Reality. The Hague: Nijhoff.

Sjölander, Sverre 2002. Naturens budbärare : från djursignaler till människospråk. Nora: Nya Doxa.

Smith, Barry 2000. Truth and the visual field. In: Petitot, Jean; Varela, Francisco J.; Pachoud, Bernard; Roy, Jean-Michel (eds.), Naturalizing Phenomenology: Issues in Contemporary Phenomenology and Cognitive Science. Stanford: Stanford University Press, 317-329.

Smith, Barry; Varzi, Achille 1999. The niche. Nô̂s 33(2): 198-222.

Sonesson, Göran 1988. Methods and Models in Pictorial Semiotics. (Report from the Semiotics project.) Lund: Lund University.

- 1989a. Pictorial Concepts. Inquiries into the Semiotic Heritage and its Relevance for the Analysis of the Visual World. Lund: Aris/Lund University Press.

- 1989b. Semiotics of Photography. On Tracing the Index. (Report from the Semiotics project.) Lund: Lund University.

- 1992a. Bildbetydelser. Inledning till bildsemiotiken som vetenskap. Lund: Studentlitteratur.

- 1992b. The semiotic function and the genesis of pictorial meaning. In: Tarasti, Eero (ed.), Center/Periphery in Representations and Institutions. Proceedings from the Conference of The International Semiotics Institute, Imatra, Finland, July 16-21, 1990. Imatra: Acta Semiotica Fennica, 211-256.

- 1993. Pictorial semiotics, Gestalt psychology, and the ecology of perception. Semiotica 99(3/4): 319-399.

- 1994. Prolegomena to the semiotic analysis of prehistoric visual displays. Semiotica 100(3/4): 267-332.

- 1995a. On pictorality: The impact of the perceptual model in the development of visual semiotics. In: Sebeok, Thomas A.; Umiker-Sebeok, Jean (eds.), The semiotic web 1992/93: Advances in Visual Semiotics. Berlin: Mouton de Gruyter, 67-108.

- 1995b. Indexicality as perceptual mediation. In: Pankow, Christiane (ed.), Indexicality. (SSKKII Report 9604.) Gothenburg: Gothenburg University, 127-143.

- 1996. An essay concerning images: From rhetoric to semiotics by way of ecological physics. Semiotica 109(1/2): 41-140.

- 1998a. That there are many kinds of pictorial signs. Visio 3(1): 33-54.

- 1998b. The concept of text in cultural semiotics. Sign Systems Studies 26: 83114. 
- 1999. Post-photography and beyond: From mechanical reproduction to digital production. Visio 4(1): 11-36.

- 2000a. Iconicity in the ecology of semiosis. In: Johansson, Troels Deng; Skov, Martin; Brogaard, Berit (eds.), Iconicity - A Fundamental Problem in Semiotics. Aarhus: NSU Press, 59-80.

- 2000b. Ego meets Alter: The meaning of otherness in cultural semiotics. Semiotica 128(3/4): 537-559.

- 2001a. The pencils of nature and culture: New light on — and in - the Lifeworld. Semiotica 136(1/4): 27-53.

- 2001b. De l'iconicité de l'image à l'iconicité des gestes. In: Cavé, Christian; Guaïtella, Isabelle; Santi, Serge (eds.), Oralité et gestualité. Actes du colloque ORAGE 2001. Paris: L'Harmattan, 47-58.

- 2001c. From semiosis to ecology: On the theory of iconicity and its consequences for an ontology of the lifeworld. Visio 6(2/3): 85-110.

- 2002. The varieties of interpretation. Galáxia 4: 67-99.

- 2003. Why the mirror is a sign — and why the television picture is no mirror: Two episodes in the critique of the iconicity critique. European Journal for Semiotic Studies 15(2/4): 217-232.

- 2004. The globalisation of Ego and Alter: An essay in cultural semiotics. Semiotica 148(1/4): 153-173.

- (in press a). Iconicity strikes back: the third generation — or why Eco still is wrong. In: Carani, Marie (ed.), Actes du 6ème Congrès de l'Association internationale de sémiotique visuelle, Québec, octobre 2001.

- (in press b). The extensions of man revisited: From primary to tertiary embodiment. In: Krois, John (ed.), The Body and Embodiment. London: Rouledge.

- (in press c). From the meaning of embodiment to the embodiment of meaning. In: Ziemke, Tom; Zlatev, Jordan; Frank, Roz; Dirven, René (eds.), Body, Language and Mind. Vol 1. Embodiment. Berlin: Mouton.

Stjernfelt, Frederik 2000. An idea that changed the world. Cybernetics and Human Knowing, 7(1): 77-82.

- 2001. Biology, abstraction, schemata. In: Brogaard, Berit; Smith, Barry (eds.), Rationality and Irrationality: Proceedings of the Kirchberg Wittgenstein Conference 2000. Vienna: Hoelder-Pichler-Tempsky, 341-361.

Thom, René 1973. De l'icône au symbole. Cahiers Internationaux du Symbolisme 22/23: 85-106.

Tomasello, Michael 1999. The Cultural Origins of Human Cognition. Cambridge: Harvard University Press.

Trevarthen, Colwyn; Logotheti, Katerina 1989. Child and culture: Genesis of cooperative knowing. In: Gellatly, Angus; Rogers, Don; Sloboda, John (eds.), Cognition and Social Worlds. Oxford: Clarendon Press, 37-56.

Tversky, Amos 1977. Features of similarity. Psychological Review 84(4): 327-352.

Tversky, Amos; Gati, Itamar 1978. Studies of similarity. In: Rosch, Eleanor; Lloyd, Barbara B. (eds.), Cognition and Categorization. Hillsdale: Erlbaum, 79-98. 
Uexküll, Jakob von 1956. Streifzüge durch die Umwelten von Tieren und Menschen. Bedeutungslehre. Hamburg: Rowohlt.

- 1973 [1928]. Theoretische Biologie. Frankfurt am Main: Suhrkamp.

— 1982 [1940]. The theory of meaning. Semiotica 42(1): 25-82.

Uspenskij, Boris 1976. Semiotics of the Russian Icon. Lisse: Peter de Ridder Press.

Varela, Francisco; Thompson, Evan; Rosch, Eleanor 1991. The Embodied Mind: Cognitive Science and Human Experience. Cambridge: The MIT Press.

Vygotsky, Lev 1962. Thought and Language. Cambridge: MIT Press.

- 1978. Mind in Society: The Development of Higher Psychological Processes. Cambridge: Harvard University Press.

Winner, Ellen 1982. Invented Worlds: The Psychology of the Arts. Cambridge: Harvard University Press.

Ziemke, Tom; Sharkey, Noel E. 2001. A stroll through the worlds of robots and animals: Applying Jakob von Uexküll's theory of meaning to adaptive robots and artificial life. Semiotica 134(1/4): 701-746.

Zlatev, Jordan 2002. Mimesis: The 'missing link' between signals and symbols in phylogeny and ontogeny. In: Pajunen, Anneli (ed.), Mimesis, Sign, and the Evolution of Language. Turku: University of Turku, 93-122.

- 2003. Meaning = Life (+ Culture). An outline of a unified biocultural theory of meaning. Evolution of Communication 4(2): 253-296.

\section{Значение значения в биологии и когнитивных науках: семиотическая реконструкция}

Цель статьи - объединить разные концепции значения, разработанные в семиотике, биологии и когнитивных науках, чтобы стало возможным формулировать вопросы, касающиеся эволюции. Концепция знака в семиотике, как и понятие репрезентации в когнитивных науках, зачастую либо использовались настолько широко, что стали бессодержательными, либо же их отвергали вообще. Мои более ранние исследования о понятиях иконичности и «картинности» заставляли меня формулировать понятие знака в традиции как Пирса, так и Соссюра. Мои работы последнего времени об эволюции семиотических средств (как, например, язык, жест, картина) доказали необходимость обращения к более точному понятию знака. Для дефиниции понятия “знак" я опираюсь на понятие семиотической функции (в понимании Пиаже) и на понятие аппрезентации, взятое у Гуссерля. В первой части настоящей статьи я сравниваю семиотику и когнитивные науки, в особенности в связи с трактовкой параллельных понятий репрезентация и знак. Вторая 
часть касается книги Терренса Дикона The Symbolic Species, которая является до сих пор самой влиятельной попыткой объединить семиотику и когнитивные науки. Я показываю, что употребление Диконом понятий иконичность, индексальность и символичность является не только противоречащим канону Пирса, но и довольно бесплодным для понимания эволюции и развития семиотических средств. Именно это является причиной, почему я предпочитаю отгородить понятие знака от понятий иконичности, индексальности и символичности, которые только при комбинировании со знаком могут стать основой для иконов, индексов и символов, но которые имеют кроме этого и другое, более элементарное употребление в области перцепции. В третьей части рассматриваются некоторые биосемиотические употребления понятия значения, которые расходятся с пониманием знака, представленным в первой части. Тут мы имеем дело с значением в его общем, связанном с отбором и организацией, значении. Хотя я считаю возможным соотнесение пирсовской интерпретации с идеей функционального круга Юкскюлла и со значением как функцией, как это описывают Эммехе и Хоффмейер, - все же я утверждаю, что подобное понимание значения отличается от концепта, содержащегося в знаке. В заключение я предлагаю, что для охвата различий “значения” (в широком смысле) и “знака" (специфицированного в традиции Пиаже-Гуссерля) нужно использовать большее количество порогов значения, чем это предлагается, например, Калеви Куллем.

\section{Tähenduse tähendus bioloogias ja kognitiivteadustes: semiootiline rekonstruktsioon}

Artikli eesmärgiks on ühendada semiootikas, bioloogias ja kognitiivteadustes välja arendatud tähenduse kontseptsioone viisil, mis võimaldaks evolutsiooni ja arenguga seotud küsimuste formuleerimist. Märgi kontseptsiooni semiootikas, nagu ka representatsiooni mõistet kognitiivteadustes on kasutatud kas sedavõrd laiana, et nad on muutunud peaaegu sisutuks, või on nad pikemata tagasi lükatud mõne eelarvamuse tõttu nende tähenduse kohta. $\mathrm{Mu}$ varasemad uurimused ikoonilisuse ja pildilisuse mõistete kohta on sundinud mind sõnastama märgi mõiste vaikimisi eeldatud tähendusi nii Saussure'i kui Peirce'i traditsioonis. Mu viimase aja tööd semiootiliste vahendite (nagu näiteks keel, žest ja pildid) evolutsiooni ja arengu kohta on tõestanud vajadust pöörduda täpsustatuma 
märgi mõiste poole. Et defineerida märki, võtan ma lähtekohaks semiootilise funktsiooni mõiste, nii nagu seda on iseloomustanud Piaget, ja appresentatsiooni mõiste, nagu seda on defineerinud Husserl. Käesoleva artikli esimeses osas vaatlen ma kognitiivteaduste ja semiootika mõningaid sarnasusi ja erinevusi, eelkõige seoses paralleelsete mõistetega representatsioon ja märk. Teine osa puudutab Terrence Deacon'i teost The Symbolic Species, mis on seni ilmselt kõige olulisem katse ühendada kognitiivteadusi ja semiootikat. Ma näitan, et mõistete ikoonilisus, indeksiaalsus ja sümbolilisus kasutus Deaconi poolt pole mitte ainult väär Peirce'i kaanoni suhtes, vaid ka üsna kasutu, mõistmaks semiootiliste vahendite evolutsiooni ja arengut. See on põhjuseks, miks ma eelistan eristada märgi mõistet ikoonilisusest, indeksiaalsusest ja sümbolilisusest, mis alles kombineerudes märgiga saavad panna aluse ikoonidele, indeksitele ja sümbolitele, kuid millel on lisaks sellele ka teine, elementaarsem kasutus taju valdkonnas. Kolmandas osas vaatlen ma mõnesid biosemiootilisi tähenduse mõiste kasutusi, mis, nagu ma näitan, ei mõista märki säärasel viisil, nagu seda on iseloomustatud käesoleva artikli esimeses osas. Seal on tegu tähendusega üldisemas, valiku ja organisatsiooni mõttes, mis on tähenduse elementaarsem tähendus. Olgugi, et pean võimalikuks Peirce'i interpretatsiooni, milles on vastavus Uexkülli funktsiooniringi ideega ning tähendust kui funktsiooni, nagu seda on kirjeldanud eeskätt C. Emmeche ja J. Hoffmeyer, väidan ma, et sellise tähenduse mõiste sisu on teistsugune kui märgi kontseptis sisalduv. Lõpetuseks panen ma ette, et tähenduse (laias mõistes) ja märgi (nii nagu seda on täpsustatud Piaget'-Husserli traditsioonis) erinevuste hõlmamiseks on vaja rakendada veelgi rohkem tähenduse lävesid kui seda pakub välja näiteks K. Kull. 